\title{
Review Article \\ Redox Signaling as a Therapeutic Target to Inhibit Myofibroblast Activation in Degenerative Fibrotic Disease
}

\author{
Natalie Sampson, ${ }^{1}$ Peter Berger, ${ }^{2}$ and Christoph Zenzmaier ${ }^{3}$ \\ ${ }^{1}$ Division of Experimental Urology, Department of Urology, Innsbruck Medical University, Anichstrasse 35, A-6020 Innsbruck, Austria \\ ${ }^{2}$ Institute for Biomedical Aging Research, University of Innsbruck, 6020 Innsbruck, Austria \\ ${ }^{3}$ Department of Internal Medicine III, Innsbruck Medical University, Anichstrasse 35, A-6020 Innsbruck, Austria
}

Correspondence should be addressed to Natalie Sampson; natalie.sampson@i-med.ac.at and

Christoph Zenzmaier; christoph.zenzmaier@i-med.ac.at

Received 5 October 2013; Accepted 6 January 2014; Published 20 February 2014

Academic Editor: David Vauzour

Copyright (C) 2014 Natalie Sampson et al. This is an open access article distributed under the Creative Commons Attribution License, which permits unrestricted use, distribution, and reproduction in any medium, provided the original work is properly cited.

\begin{abstract}
Degenerative fibrotic diseases encompass numerous systemic and organ-specific disorders. Despite their associated significant morbidity and mortality, there is currently no effective antifibrotic treatment. Fibrosis is characterized by the development and persistence of myofibroblasts, whose unregulated deposition of extracellular matrix components disrupts signaling cascades and normal tissue architecture leading to organ failure and death. The profibrotic cytokine transforming growth factor beta (TGF $\beta$ ) is considered the foremost inducer of fibrosis, driving myofibroblast differentiation in diverse tissues. This review summarizes recent in vitro and in vivo data demonstrating that TGF $\beta$-induced myofibroblast differentiation is driven by a prooxidant shift in redox homeostasis. Elevated NADPH oxidase 4 (NOX4)-derived hydrogen peroxide $\left(\mathrm{H}_{2} \mathrm{O}_{2}\right)$ supported by concomitant decreases in nitric oxide (NO) signaling and reactive oxygen species scavengers are central factors in the molecular pathogenesis of fibrosis in numerous tissues and organs. Moreover, complex interplay between NOX4-derived $\mathrm{H}_{2} \mathrm{O}_{2}$ and NO signaling regulates myofibroblast differentiation. Restoring redox homeostasis via antioxidants or NOX4 inactivation as well as by enhancing NO signaling via activation of soluble guanylyl cyclases or inhibition of phosphodiesterases can inhibit and reverse myofibroblast differentiation. Thus, dysregulated redox signaling represents a potential therapeutic target for the treatment of wide variety of different degenerative fibrotic disorders.
\end{abstract}

\section{Introduction: Fibrosis and Degenerative Fibrotic Diseases}

The wound healing response in which damaged/dead cells are replaced following acute injury (such as infection, autoimmune reaction, or mechanical injury) is essential to maintain tissue architecture and function [1-4]. However, if the healing process continues unchecked, for example, due to repeated/chronic injury, fibrosis ensues as characterized by substantial deposition and remodeling of the extracellular matrix (ECM) and permanent scar tissue formation, which destroys correct tissue architecture and may ultimately lead to organ failure and death [1-4].

There are numerous degenerative fibrotic diseases, including multisystemic disorders such as systemic sclerosis, chronic graft versus host disease, and nephrogenic systemic fibrosis as well as organ-specific diseases, for example, cardiac fibrosis, idiopathic pulmonary fibrosis (IPF), intestinal fibrosis, liver cirrhosis, progressive kidney disease, macular degeneration, and benign prostatic hyperplasia (BPH) [1-3, 5-12]. In addition, a multitude of disorders with prominent tissue remodeling also have a significant fibrotic component, including asthma, atherosclerosis, and the reactive stromal response to solid tumors, such as breast, liver, and prostate cancer [13-16]. Thus, it is perhaps not surprising that approximately $45 \%$ of the mortality in Western nations is attributed to fibrotic diseases, a figure that is certainly even higher in less developed countries [12].

Despite the considerable morbidity and mortality caused by fibrosis, there are currently no effective treatments for 
many of these diseases and no approved antifibrotic therapies. In part, this is due to our current lack of knowledge regarding (i) the precise etiology of the initiating injury/infection and (ii) the mechanisms that drive fibrosis progression. Thus, a better understanding of the molecular pathways underlying fibrosis and the initiating signals/causes is urgently required for the development of effective therapeutic strategies. This review focuses on accumulating evidence that redox signaling plays a fundamental and integral role in the molecular pathogenesis of fibrosis in many different tissues and organs and as such represents a potential therapeutic target for the treatment of wide variety of different fibrotic disorders.

\section{The Myofibroblast: Biology, Origin, and Role in Fibrosis}

Fibrotic diseases are clearly distinct in their etiology and clinical manifestation. Nonetheless, fibrogenesis in most organs and tissues progresses in a remarkably similar manner, characterized in particular by the development and persistence of large numbers of myofibroblasts $[3,7,9,12]$. During the normal wound healing response, myofibroblasts accumulate to promote wound closure by virtue of their contractile and ECM- and growth factor-secreting properties, with the latter serving to attract epithelial cells, a process termed "reepithelialization". Normal tissue function and architecture are restored upon completion of reepithelialization via poorly understood mechanisms that result in massive apoptosis of myofibroblasts and vascular cells, which are subsequently cleared from the wound site $[7,17,18]$. Tissue and organ fibrosis are thought to arise from failure of myofibroblast apoptosis during wound healing $[3,19]$. Again, however, the mechanisms underlying this apparent "apoptosis-resistant" myofibroblast phenotype remain ill-defined [20]. The resulting persistent myofibroblast activation leads to excessive ECM deposition, altered growth factor signaling and consequently cellular proliferation, progressive remodeling and destruction of normal tissue architecture, organ dysfunction, and failure $[3,19,21]$. Thus, the myofibroblast is widely considered the main effector cell of fibrosis and thereby a major therapeutic target.

Myofibroblasts are a specialized cell type that combines the ECM-producing characteristics of fibroblasts with the cytoskeletal and contractile properties of smooth muscle cells (SMCs) as reviewed recently [2]. Myofibroblasts are defined by (i) their de novo expression of alpha-smooth muscle cell actin ( $\alpha$-SMA, encoded by the gene ACTA2) in stress fibers and (ii) contractile force. The cellular origin of myofibroblasts remains somewhat controversial but may differ depending on the organ and/or the initiating stimulus (reviewed [2, 22]). Myofibroblasts have been described to originate from differentiation of vascular SMCs, bone marrow-derived fibrocytes, hepatic stellate cells, resident epithelial cells via epithelial-to-mesenchymal transition, and endothelial cells via endothelial-to-mesenchymal transition [3, 23]. However, although these cell types undergo differentiation into myofibroblasts in vitro, the extent of their contribution to the myofibroblast pool in vivo is the subject of considerable debate. Rather, it is widely accepted that myofibroblasts predominantly originate from the differentiation of local tissue fibroblasts [23].

Fibroblast-to-myofibroblast differentiation occurs via a two-step process. Following injury or during chronic inflammation, changes in mechanical tension of the ECM are transmitted to the fibroblast cytoskeleton via RhoA/ROCK signaling [24]. Consequently, fibroblasts adopt an "activated" phenotype (termed "protomyofibroblast") and deposit new ECM components [25]. Soluble factors and cytokines, in particular the splice variant ED-A of cellular fibronectin and profibrotic cytokine $\operatorname{TGF} \beta$, which are produced initially by platelets and infiltrating leukocytes at the wound site, are major inducers of fibroblast-to-myofibroblast differentiation [25]. However, protomyofibroblasts and myofibroblasts themselves also secrete and activate TGF $\beta$ thus generating an autocrine feed-forward loop driving continued myofibroblast differentiation [26, 27] (Figure 1). It may be noted, however, that, although inflammation frequently occurs prior to fibrosis, fibrogenesis can also occur independently of inflammatory mechanisms indicating that inflammation is not always the driving initiator [28].

Although several TGF $\beta$-independent mechanisms of fibrosis have been described, such as interleukins 4 and 13 and platelet-derived growth factor (reviewed $[34,35]$ ), TGF $\beta 1$ is widely considered the foremost inducer of fibrosis and drives myofibroblast differentiation in cells of diverse histological origin, including breast, skin, prostate, kidney, heart, lung, and liver [36-42]. Consistently, elevated TGF $\beta 1$ levels and signaling are observed in many fibrotic disorders $[19,43-$ 50]. TGF $\beta 1$ exerts its effects via downstream activation of canonical Smad2/3 signaling or via noncanonical Smadindependent activation of mitogen-activated protein kinase (MAPK) and PI3 kinase/Akt pathways [2, 26, 51]. Collectively, signaling via these pathways leads to ECM deposition and secretion of paracrine- and autocrine-acting growth factors $[26,52]$. Notably, the ECM can directly bind to and release growth factors; for example, heparan sulfate can bind to and release fibroblast growth factor 2 [53]. On the one hand, such interactions sequester growth factors thereby protecting them from degradation but can also enhance their bioactivity due to increased half-life [54]. Moreover, indirect interactions are required for signal transduction of some growth factors; for example, integrin binding is necessary for induction of angiogenesis by vascular endothelial cell growth factor [55]. Thus, remodeling and enhanced deposition of ECM in fibrosis contributes to disease pathogenesis not only by disrupting normal tissue architecture but also by modulating cellular signaling cascades (Figure 1).

TGF $\beta$ undoubtedly plays a pivotal role in pathogenic fibrogenesis. Therapeutic approaches designed to interfere with downstream TGF $\beta$ signaling processes that culminate in myofibroblast activation may represent an alternative viable strategy for the treatment of fibrotic disease. In this respect, a convincing body of data implicates dysregulated redox signaling by NADPH oxidase 4 (NOX4) and nitric oxide (NO) in the pathophysiology of fibrosis. 


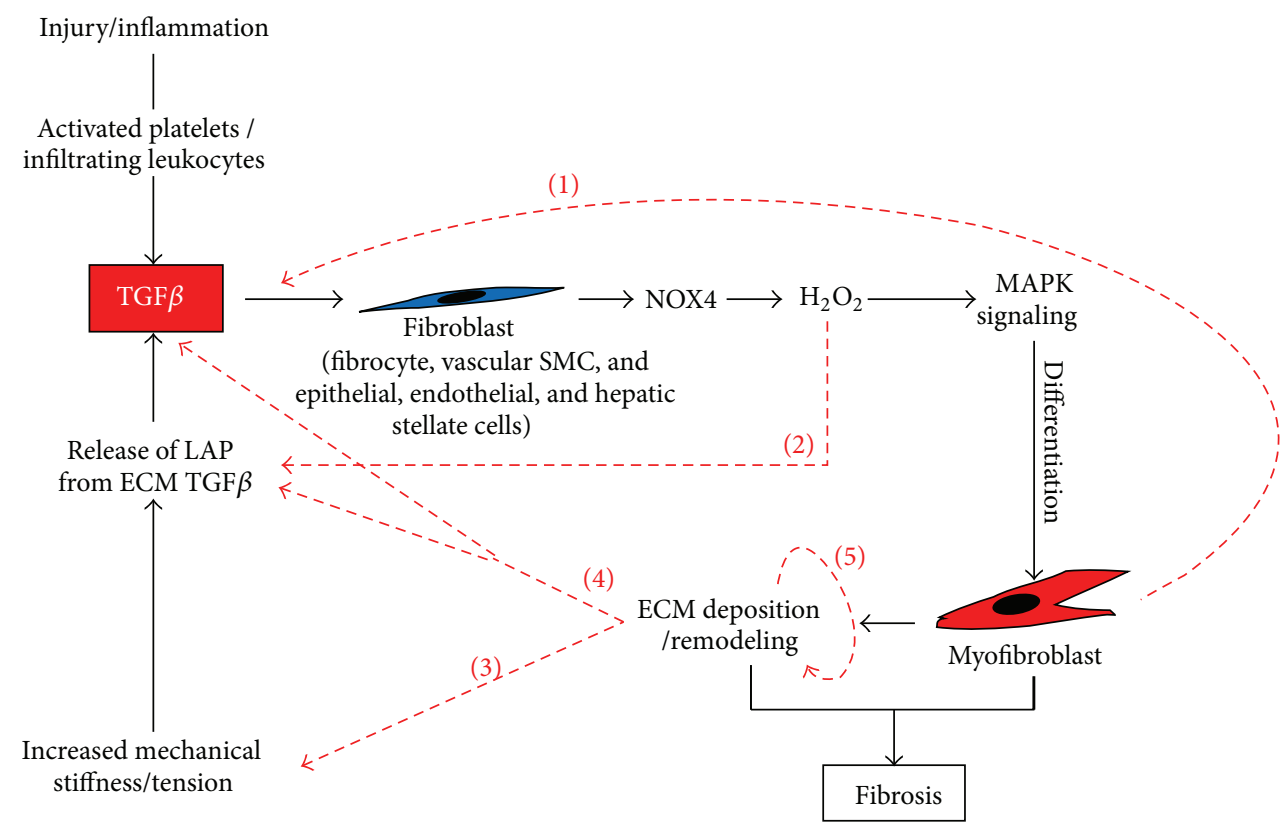

FIGURE 1: Feed-forward loop of TGF $\beta$ activation and myofibroblast differentiation in fibrosis. Upon injury activated platelets, infiltrating inflammatory and vascular cells secrete $\mathrm{TGF} \beta$, which acts on local fibroblasts and other precursor cells (e.g., hepatic stellate cells, fibrocytes) inducing their production of NOX4-derived $\mathrm{H}_{2} \mathrm{O}_{2}$. Consequently, downstream MAPK signaling cascades are activated resulting in differentiation into myofibroblasts, whose production of ECM components facilitates wound closure. Prolonged injury or inflammation leads to persistent myofibroblast activation via a feed-forward loop driven by several different factors. For example, myofibroblasts themselves secrete and produce large amounts of active TGF $\beta$ and thereby generate an autocrine feed-forward loop that is characteristic of persisting myofibroblast activity (1) [27]. Activation of latent TGF $\beta$ in ECM deposits via dissociation of latency associated peptide (LAP) is promoted by various mechanisms, including direct oxidative modification (2) [29-31]. Thus, NOX4-derived $\mathrm{H}_{2} \mathrm{O}_{2}$ may drive myofibroblast differentiation not only by oxidative modulation of MAPK signaling cascades that culminate in downstream transcriptional programs of differentiation [26], but also via its ability to freely diffuse across biological membranes and oxidatively modulate components in the extracellular space. Myofibroblasts also secrete high levels of ECM components. The resulting increase in mechanical tension and tissue stiffness can activate ECM-bound latent TGF $\beta$ due to mechanical pulling of LAP by specific integrins at the myofibroblast cell surface (3) [32]. Thereby, TGF $\beta$ is released and activated from the latent complex, which in turn drives further myofibroblast contraction and differentiation as well as ECM deposition [25]. In addition to this physical mechanism of TGF $\beta$ activation by the remodeled ECM, components of the remodeled ECM can modulate TGF $\beta$ signaling in a biochemical manner (4), for example, latent TGF $\beta$ binding proteins, fibrillins, fibulins, fibronectin, and proteoglycans (reviewed [33]). Moreover, a number of targets downstream of TGF $\beta$ signaling provide feedback modulation of the ECM either directly or indirectly, for example, thrombospondin-1 (TSP-1), collagens/ECM components themselves, and ECM remodeling components such as matrix metalloproteinases (5) (MMP2, -9), plasminogen activator inhibitor (PAI-1), and tissue inhibitors of metalloproteinases (TIMPs) [26]. Thus, the stiffened/remodeled ECM together with autocrine production of TGF $\beta$ and NOX4-derived $\mathrm{H}_{2} \mathrm{O}_{2}$ actively perpetuate TGF $\beta$ signaling and myofibroblast differentiation leading to fibrosis.

\section{Signaling by NOX4-Derived Reactive Oxygen Species in the Regulation of Myofibroblast Differentiation}

High levels of free radicals can result in nonspecific oxidative damage to cell structures and biomolecules. However, when produced in a regulated manner, reactive oxygen species (ROS), NO, and reactive nitrogen species play a critical role as biological second messengers in a variety of cellular processes, including myofibroblast differentiation [56]. NADPH oxidase (NOX) enzymes are unique in that ROS production is their primary and sole function [57]. This is in contrast to ROS-producing enzyme systems such as xanthine oxidase or uncoupled endothelial NO synthase, whose production of ROS occurs secondary to their primary function.
The seven members of the NOX family catalyze the transfer of electrons across biological membranes from NADPH to oxygen thereby generating superoxide $\left(\mathrm{O}_{2}{ }^{--}\right)$[58]. However, the major detected product and primary effector ROS of the constitutively active NOX4 is hydrogen peroxide $\left(\mathrm{H}_{2} \mathrm{O}_{2}\right)$, although this most likely is a result of rapid superoxide dismutation [59-61]. It is thought that a highly conserved histidine residue within the E-loop of NOX4 promotes rapid dismutation of superoxide before it leaves the enzyme [61], although this aspect of NOX4 biology requires further clarification. Irrespectively, the greater stability but lower reactivity of $\mathrm{H}_{2} \mathrm{O}_{2}$ compared to superoxide is consistent with a signaling function of NOX4-derived ROS $[26,62,63]$. NOXderived ROS exert their signaling functions by modulating biological activity of target proteins such as transcription 

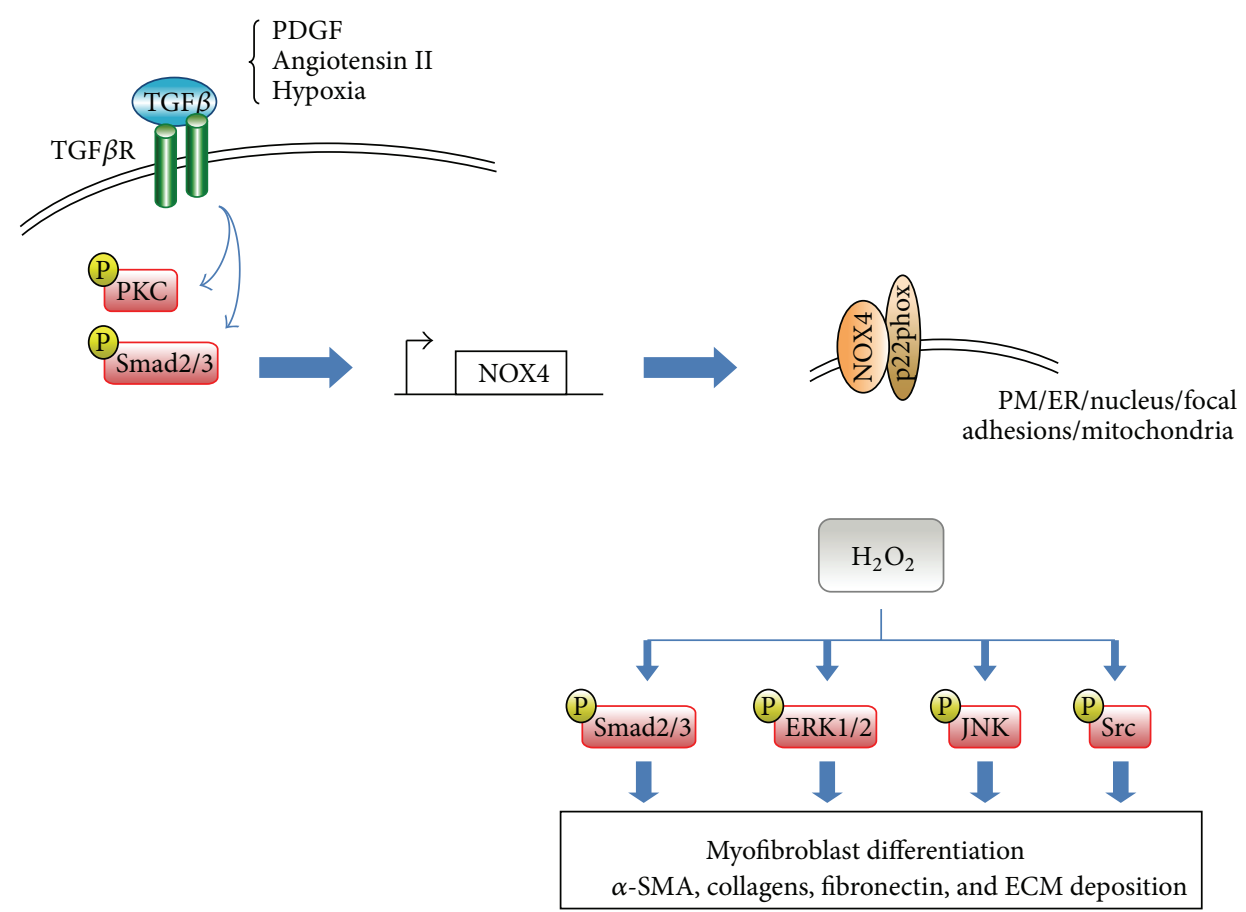

FIgURE 2: Signaling pathways that activate NOX4 and downstream targets of NOX4-derived ROS in myofibroblasts. NOX4 activity is predominantly regulated at the transcriptional level $[59,65]$. TGF $\beta$ is one of the main inducers of NOX4 during myofibroblast activation. Additionally, hypoxia, angiotensin II, and platelet-derived growth factor (PDGF) have also been shown to activate NOX4 expression leading to myofibroblast activation; however, this most likely occurs as a result of their indirect activation of TGF $\beta$ signaling [75-77]. Upon binding of TGF $\beta$ ligand, heteromeric complexes of TGF $\beta$ receptor type I and type II recruit and activate the canonical signal transducers Smad $2 / 3$ as well as less well understood noncanonical signal transducers, such as mitogen-activated protein kinases (MAPKs) and protein kinase C (PKC). TGF $\beta$ signal transducers subsequently activate the transcription of target genes that include NOX4. TGF $\beta$-mediated induction of NOX4 expression has largely shown to be Smad2/3-dependent $[39,40]$; however, PKC has also been implicated in TGF $\beta$-dependent upregulation of NOX4 [78]. The subcellular localization of NOX4 appears to be cell-, tissue-, and perhaps even context-specific with its reported localization to the plasma membrane (PM), endoplasmic reticulum (ER), nucleus, focal adhesions, and mitochondria [62]. NOX4 requires the cofactor p22 $2^{\text {phox }}$ for production of ROS, of which predominantly $\mathrm{H}_{2} \mathrm{O}_{2}$ is detected [59-61]. NOX4-derived $\mathrm{H}_{2} \mathrm{O}_{2}$ activates signaling intermediates such as Smad2/3, ERK1/2, JNK and Src [26, 39, 40,77, 79-81], which subsequently induce the transcription of downstream target genes, such as $\alpha$-smooth muscle cell actin ( $\alpha$-SMA), collagens, and fibronectin leading to ECM deposition and myofibroblast differentiation/activation.

factors, MAPKs, protein tyrosine phosphatases (PTPs), and protein tyrosine kinases via reversible oxidation of thiol groups of low pKa cysteine residues [63, 64].

Unlike other NOX isoforms, NOX4 is constitutively active with primary regulation occurring at the transcriptional level $[59,65]$. NOX4 expression is activated in vascular SMCs and fibroblasts by several cytokines implicated in the pathogenesis of fibrosis, including $\operatorname{TGF} \beta$, angiotensin II, and platelet-derived growth factor [5] and elevated NOX4 levels are observed in tissues bearing hallmarks of fibrosis (Figure 2). For example, NOX4 mRNA levels specifically correlated with the myofibroblast phenotype in benign prostatic tissue [26]. Similarly, NOX4 expression was higher in pulmonary fibroblasts from patients with IPF compared with controls and correlated with myofibroblast marker expression [66]. In addition, NOX4 was found to be expressed in fibroblastic foci in the lung of IPF patients and two mouse models of pulmonary fibrosis [67]. Recently, high levels of NOX4, which colocalized with $\alpha$-SMA, were observed in liver biopsy samples from patients with autoimmune hepatitis [42]. These observations together with findings from functional studies indicate that elevated NOX4-derived ROS play a critical role in the pathophysiology of numerous fibrotic disorders (Figures 1-3) [26, 40, 67-71]. For example, we demonstrated that NOX4-derived ROS drive myofibroblast differentiation of prostatic fibroblasts in response to TGF $\beta 1$ [26]. Similar findings were observed for cardiac, pulmonary, renal, and adventitial fibroblasts and hepatic stellate cells [39, 40, 42, $66,67,72]$. In vascular endothelial cells, NOX4 also mediates TGF $\beta 1$-induced cytoskeletal remodeling and maintains the differentiated phenotype of vascular SMCs [73, 74].

Several in vivo studies have provided more definitive evidence that NOX4-derived ROS play a direct role in the pathogenesis of fibrosis. For example, inhibition of NOX4 via genetic deletion, antisense oligonucleotides, siRNA, or NOX inhibitors attenuated disease progression in rodent models of pulmonary, renal, and liver fibrosis [42, 67, 82-84].

NOX4 induction appears to contribute to fibrogenesis not via oxidative stress-induced damage $[26,62,63]$, but rather by chronic dysregulation of downstream signaling pathways (Figure 2). The precise oxidative target(s) of NOX4derived ROS that culminate in myofibroblast differentiation 


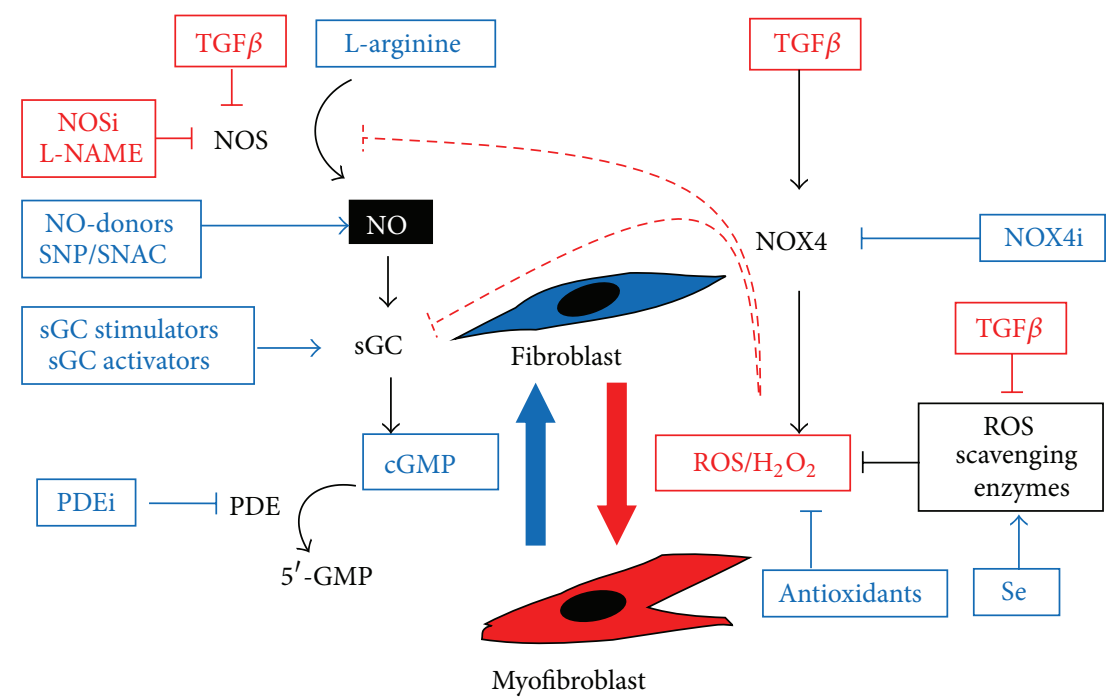

Figure 3: Potential therapeutic targeting of myofibroblast differentiation. Myofibroblast differentiation plays a central role in the etiology of fibrosis. TGF $\beta$, which is widely considered the foremost inducer of fibrosis, induces NOX4 resulting in a persistent prooxidant shift in intracellular redox homeostasis mediated via ROS (in particular $\mathrm{H}_{2} \mathrm{O}_{2}$ ), which modulates downstream phosphorylation signaling cascades and transcriptional events culminating in fibroblast-to-myofibroblast differentiation. The concomitant downregulation of selenium (Se)dependent ROS scavenging enzymes by TGF $\beta$ further potentiates NOX4-derived ROS signaling. In parallel, TGF $\beta$ and $\mathrm{H}_{2} \mathrm{O}_{2}$ attenuate NO signaling, which is associated with the fibroblast phenotype, via attenuation of NOS and sGC activities. Likewise, NOS inhibitors (NOSi/L-NAME) attenuate NO signaling and aggravate fibrosis. Fibroblast-to-myofibroblast differentiation and subsequent tissue fibrosis are reversible processes. Thus, targeting persistent NOX4-derived ROS levels in the diseased tissue by NOX4 inhibitors (NOX4i) or by ROS scavenging with Se or antioxidants results in inhibition of myofibroblast differentiation and, moreover, in dedifferentiation/inactivation of myofibroblasts to a quiescent fibroblast-like phenotype. Similarly, enhancement of NO signaling by administration of the NOS substrate L-arginine, NO-donors (SNP/SNAC), sGC stimulators/activators, or PDE inhibitors (PDEi) maintains the fibroblast phenotype or induces dedifferentiation/inactivation of preexisting myofibroblasts.

in response to TGF $\beta$ remain(s) largely unknown. However, TGF $\beta 1$-induced NOX4-derived ROS have been shown to directly oxidatively inactivate MKP1, a dual specificity MAPK phosphatase that targets JNK and p38 [79]. Consistently, JNK phosphorylation by NOX4-derived ROS was essential for TGF $\beta 1$-induced myofibroblast differentiation of prostatic fibroblasts and cardiomyocyte differentiation of pluripotent embryonal carcinoma cells $[26,80]$. Other targets activated by NOX4-derived ROS in fibrogenic signaling cascades include ERK1/2 and Src $[39,81]$. Thus, it appears that the NOX4-dependent fibrotic response can be mediated via multiple oxidative targets (Figure 2). Interestingly, activation and release of TGF $\beta$ from its latency association peptide (LAP) are also induced by oxidative modification of LAP with free radicals capable of stimulating TGF $\beta$ expression and secretion in many cell types $[29,85]$ (Figure 1).

Although NOX 4 induction by TGF $\beta 1$ does not typically result in oxidative stress-induced damage in fibroblasts [26, $62,63]$, primary alveolar epithelial cells exposed to TGF $\beta 1$ undergo apoptosis in a NOX4-dependent manner [86], an event that can also be indirectly mediated via paracrine release of $\mathrm{H}_{2} \mathrm{O}_{2}$ by activated myofibroblasts [87]. Thus, NOX4 may promote fibrosis not only by driving cytokine-induced fibroblast-to-myofibroblast differentiation but also by impairing epithelial regenerative capacity during wound healing.

In summary, whilst acute induction of NOX4 may be beneficial in inducing the myofibroblast phenotype during wound healing, the persistence of myofibroblasts together with autocrine TGF $\beta$ signaling may result in chronic NOX4 activation and ROS production resulting in a selfperpetuating cycle of myofibroblast differentiation and accumulation, fibrosis, and organ dysfunction (Figure 1). Thus, targeting elevated NOX4-derived ROS either directly via NOX4 inhibition or indirectly by increasing the activity of ROS scavenging enzymes represents a promising therapeutic strategy for the treatment of diverse fibrotic pathologies (Figure 3).

There are numerous ROS-scavenging systems that maintain cellular redox homeostasis; however, of particular interest are the selenium (Se)-dependent enzymes. We observed downregulation of the Se transporter SEPP1 and Se-containing ROS scavengers glutathione peroxidase 3 (GPX3) and thioredoxin reductase 1 (TXNRD1) during TGF $\beta 1$-mediated prostatic myofibroblast differentiation [26]. Moreover, SEPP1 was specifically lost in tumor-associated stroma of prostate cancer patients, indicating reduced activity of ROS scavenging enzymes in the diseases tissue [26]. Se is an essential trace element that is incorporated as selenocysteine into the active sites of GPX3 and TXNRD1 enzymes and required for proper protein folding/function [88]. Consistent with the role of SEPP1 in delivering Se to peripheral tissues for selenoprotein biosynthesis $[89,90]$, exogenous Se restored expression of GPX3 and TXNRD1 as well as TXNRD1 enzyme activity, depleted TGF $\beta 1$-induced ROS downstream of NOX4 
induction, and inhibited myofibroblast differentiation of prostatic fibroblasts [26]. Similarly, exogenous Se also inhibited TGF $\beta$-mediated myofibroblast transdifferentiation of hepatic stellate cells [91]. Furthermore, we observed that exogenous Se restores morphological and molecular characteristics typical of the fibroblast phenotype to in vitro differentiated prostatic myofibroblasts even in the continued presence of the TGF $\beta$ differentiation-inducing stimulus [4]. Similarly, studies employing myofibroblasts from IPF patients and a threedimensional coculture model of porcine skin fibrosis also demonstrated the potential utility of ROS scavenging in promoting myofibroblast dedifferentiation $[92,93]$. Consistently, pharmacological inhibition of NOX4 after induction of liver fibrosis in mice was shown to reduce ROS levels and significantly attenuate fibrosis [42].

Collectively, a large body of in vitro and in vivo data indicates that myofibroblast differentiation in fibrotic disorders and tumor-reactive stroma is driven by a prooxidant shift in intracellular redox signaling caused by elevated ROS and/or reduced antioxidative potential. NOX4 appears to be the major source of elevated ROS and central mediator of TGF $\beta$ induced myofibroblast differentiation in diverse tissues. Thus, restoring cellular redox homeostasis by (i) targeting NOX4, (ii) Se supplementation, and/or (iii) application of antioxidants may represent a promising therapeutic strategy for fibrotic disease (Figure 3). Moreover, rather than simply inhibiting myofibroblast differentiation to prevent disease progression, clearing the myofibroblast pool in fibrotic disorders by inducing their dedifferentiation to the nonactivated fibroblast/progenitor phenotype may be a feasible therapeutic strategy that potentially represents a curative treatment.

\section{Nitric Oxide Signaling in the Regulation of Myofibroblast Differentiation}

The free radical NO is an important signaling molecule in a variety of biological processes that is biosynthesized in vivo from L-arginine by nitric oxide synthases (NOS), involving the oxidation of NADPH and the reduction of molecular oxygen. NO signaling is mediated via activation of soluble guanylyl cyclase (sGC). The second messenger cyclic guanosine monophosphate (cGMP) that is subsequently generated by sGC regulates the activity of cGMP-dependent protein kinases such as protein kinase G (PKG), cyclic nucleotide phosphodiesterases (PDEs), and cation channels and may have other unknown effects [94].

In terms of fibroblast-to-myofibroblast differentiation, NO signaling appears to be a central pathway associated with the fibroblast phenotype (Figure 3). Treatment of dermal fibroblasts with TGF $\beta 1$ significantly reduced NOS activity and NO levels, whereas the NOS inhibitor $N_{\omega}$-nitro-Larginine methyl ester (L-NAME) synergistically potentiated TGF $\beta 1$-induced collagen production [95]. Consistently, NOS inhibition or knockout attenuated fibrosis in several animal models [96-99]. We previously demonstrated that the soluble NO donor sodium nitroprusside (SNP) dose-dependently inhibited TGF $\beta 1$-induced myofibroblast differentiation of human prostatic fibroblasts in vitro [100]. These findings are in line with suppression of TGF $\beta 1$-induced collagen production by SNP in dermal fibroblasts in vitro and attenuation of fibrosis in rodent model systems using the NOS substate L-arginine or the NO donor S-Nitroso- $N$-acetylcysteine (SNAC), respectively [95, 98, 101]. Moreover, parallel NO donation and cyclooxygenase inhibition prevented bleomycin-induced lung fibrosis in mice [102].

Since NO activates sGC, increasing sGC activity via NOindependent heme-dependent sGC stimulators represents an alternative approach to enhance NO signaling (Figure 3). Similarly to observations with NO donors, the sGC stimulator BAY 41-2272 inhibited in vitro myofibroblast differentiation of cardiac fibroblasts and dermal fibroblasts from healthy subjects and patients with systemic sclerosis [103, 104]. In vivo BAY 41-2272 limited disease progression in models of renal, cardiac, and dermal fibrosis [103-106] and similar inhibitory effects were documented for the sGC stimulator riociguat (BAY 63-2521) in rat models $[107,108]$. In contrast to sGC stimulators that require the presence of a reduced heme moiety in the prosthetic group of the enzyme, sGC activators can bind to and activate oxidized or heme-deficient sGC [109]. Under conditions of oxidative stress, the heme moiety can be oxidized and lost, rendering sGC no longer responsive to NO. Thus, these heme-independent activators may be beneficial in the treatment of a variety of diseases associated with oxidative stress [109]. Of note, the sGC activator BAY 60-2770 inhibited myofibroblast differentiation in prostatic and dermal fibroblasts (our unpublished observations) and attenuated liver fibrosis in rat models [110], whilst the sGC activator cinaciguat (BAY 58-2667) prevented disease progression in a rat model of chronic renal failure [111].

The fact that treatment with the cell-permeable cGMP analog 8-bromo-cGMP is able to mimic the inhibitory effects of enhanced NO/sGC signaling on myofibroblast differentiation clearly indicates that inhibition is mediated downstream via cGMP $[95,112]$. Thus, inhibitors of certain phosphodiesterase isoforms (PDE) represent an additional approach to enhance NO/cGMP signaling. PDEs comprise a superfamily of phosphohydrolases that degrade cellular cGMP and cAMP. PDE type 5 (PDE5), which specifically hydrolyzes cGMP, is the major therapeutic target in erectile dysfunction, and is additionally approved for the treatment of pulmonary arterial hypertension and $\mathrm{BPH}$ [113-115]. Increased PDE5 expression was observed in anti-Thyl-induced mesangial proliferative glomerulonephritis in rats and PDE5 inhibition showed beneficial antiproliferative and antifibrotic effects in vivo, indicating an active role of PDE5 in fibrogenesis [116]. We previously demonstrated that pharmacological inhibition or shRNAmediated silencing of PDE5 significantly attenuated TGF $\beta 1$ induced myofibroblast differentiation of prostatic fibroblasts in vitro [100]. Likewise, PDE5 inhibition prevented myofibroblast differentiation in fibroblasts form Peyronie's disease plaques in vitro and counteracted fibrosis in TGF $\beta 1$-induced Peyronie's disease-like plaques in rats $[117,118]$. Moreover, in lung fibroblasts PDE5 inhibition in combination with the sGC activator cinaciguat attenuated myofibroblast differentiation [41].

Similarly to exogenous $\mathrm{Se}$, we recently reported that PDE5 inhibition in in vitro differentiated prostatic myofibroblasts restored morphological and molecular characteristics typical 
of the fibroblast phenotype, indicating that enhancement of NO signaling not only prevents but also might reverse fibrosis [119]. Consistently, the NO donor SNAC induced dedifferentiation of activated hepatic stellate cells in vitro [120] and in vivo sGC stimulation by BAY 41-8543 decreased tubulointerstitial fibrosis after relief of unilateral ureteral obstruction in rats [121]. Similarly, BAY 41-2272 reduced established fibrosis in modified mouse models of dermal fibrosis [34] and PDE5 inhibition reduced myofibroblast numbers and total size of preformed TGF $\beta 1$-induced Peyronie's diseaselike plaques in rats [117]. Of note, various PDE5 inhibitors selectively increased the apoptotic index in TGF $\beta 1$-induced Peyronie's disease-like plaques in rats $[117,118]$, indicating clearance of myofibroblasts by apoptosis upon enhancement of NO signaling.

Collectively, findings from in vitro and in vivo model systems indicate that the fibroblast phenotype is maintained by NO signaling and that myofibroblast differentiation is associated with an attenuation/inhibition of the NO/sGC/cGMP signaling cascade, while stimulation of $\mathrm{NO}$ signaling is capable of even reverting myofibroblast differentiation. Thus, enhancement of NO signaling by NO donors, stimulators, and activators of sGC or inhibition of cGMP degradation via PDE inhibitors might be of therapeutic benefit for patients suffering from degenerative fibrotic disease (Figure 3).

\section{Crosstalk between NOX4/ $\mathrm{H}_{2} \mathrm{O}_{2}$ and NO Signaling Networks in the Regulation of Myofibroblast Differentiation}

The fact that elevated NO signaling attenuates and reverses myofibroblast differentiation while NOX4-derived ROS play a key role in driving differentiation in response to TGF $\beta$ indicates that the fibroblast/myofibroblast phenotype is regulated via crosstalk between both signaling pathways. The main ROS effector of NOX4 is $\mathrm{H}_{2} \mathrm{O}_{2}$ [59-61]; however, by virtue of its catalytic structure [122] its primary product like other NOX isoforms is superoxide (see chapter 3) [59-61]. Even assuming that NOX4-derived superoxide undergoes rapid dismutation, residual superoxide could potentially cross-react with $\mathrm{NO}$ signaling; for example, superoxide can react with NO generating peroxynitrite $\left(\mathrm{ONOO}^{-}\right)$, thereby depleting $\mathrm{NO}$ levels [123]. In addition, superoxide can oxidize the critical nitric oxide synthase (NOS) cofactor tetrahydrobiopterin $\left(\mathrm{BH}_{4}\right)$ leading to NOS uncoupling and superoxide generation rather than NO production [124]. Indeed, in some models, NOX4 has been implicated in the generation of peroxynitrite and subsequent NOS uncoupling [125-128]. However, since NOX4 is primarily associated with constitutive $\mathrm{H}_{2} \mathrm{O}_{2}$ production $[60,61]$, which unlike superoxide does not appear to react directly with $\mathrm{NO}$, any opposing regulation of TGF $\beta$ induced myofibroblast differentiation by NO and NOX4derived ROS signaling presumably predominantly occurs via distinct mechanisms (summarized Figure 3).

There are several mechanisms by which NOX4-derived $\mathrm{H}_{2} \mathrm{O}_{2}$ may affect $\mathrm{NO}$ signaling. $\mathrm{H}_{2} \mathrm{O}_{2}$ impaired NO production in porcine aortic endothelial cells possibly via direct oxidative inactivation of eNOS cofactors [129]. Moreover,
$\mathrm{H}_{2} \mathrm{O}_{2}$ decreased sGC expression and consequently NOdependent cGMP generation in pulmonary arterial SMCs from lambs with persistent pulmonary hypertension of the newborn and in rat aortic SMCs or freshly isolated vessels $[130,131] . \mathrm{H}_{2} \mathrm{O}_{2}$ or PTP inhibitors promoted tyrosine phosphorylation of the beta 1 subunit of sGC, presumably via Src-like kinases. Since c-Src-dependent phosphorylation of sGC has been shown to attenuate sGC activity and cGMP formation $[132,133]$, these data suggest that elevated NOX4derived $\mathrm{H}_{2} \mathrm{O}_{2}$ during myofibroblast differentiation may inactivate PTPs and/or activate Src kinase, leading to sGC phosphorylation and consequently reduced cGMP formation.

Additionally, NOX4-derived $\mathrm{H}_{2} \mathrm{O}_{2}$ and $\mathrm{NO}$ signaling may interact via common cofactors. Both NOS and NOX require $\mathrm{NADPH}$ as an electron donor for enzyme activity. Since NOX4 induction is an early event during TGF $\beta 1$ mediated differentiation [26, 40], NADPH consumption/ depletion due to elevated NOX4 activity may attenuate NOS activity and consequently NO signaling. Furthermore, opposing interaction may occur via mutually exclusive modification of NOX/NO target proteins. For example, NO activates sarco/endoplasmic reticulum $\mathrm{Ca} 2+$ ATPase (SERCA) via $S$-glutathiolation on cysteine 674, while induction of NOX4 via TGF $\beta 1$, exposure to $\mathrm{H}_{2} \mathrm{O}_{2}$, or high glucose resulted in SERCA oxidation of the same thiol group that inhibited NO-mediated S-glutathiolation [134-136].

Taken together these findings clearly indicates that $\mathrm{H}_{2} \mathrm{O}_{2}$ and $\mathrm{NO}$ appear to interact in a functionally opposing manner during myofibroblast differentiation via multiple mechanisms, whereby TGF $\beta 1$-mediated induction of NOX4derived $\mathrm{H}_{2} \mathrm{O}_{2}$ leads to downregulation of $\mathrm{NO}$ signaling and thereby promotes fibroblast-to-myofibroblast differentiation. Consistently, TGF $\beta 1$ significantly decreased NO production in dermal fibroblasts [95]. Thus, stimulating sGC generation and/or inhibiting cGMP degradation potentially counteract ROS-mediated inactivation of NO signaling to consequently prevent and reverse myofibroblast differentiation. Of note, enhancing cGMP levels inhibited and reversed differentiation without impairing NOX4 mRNA induction by TGF $\beta 1$ (our unpublished observations) [119], indicating that NO signaling acts downstream of NOX4-derived $\mathrm{H}_{2} \mathrm{O}_{2}$ production. Since treatment with 8 -bromo-cGMP is sufficient to inhibit myofibroblast differentiation [95], the $\mathrm{H}_{2} \mathrm{O}_{2}$-counteracting effects of elevated NO signaling appear to be mediated via downstream cGMP-dependent mechanisms and not via the NO radical per se.

\section{Clinical Implications}

In order to develop broadly effective antifibrotic therapies, it will be necessary to identify common features of different fibrotic disorders that affect distinct tissues and/or are initiated by different stimuli (e.g., chronic scarring of the liver due to hepatitis versus the tumor-associated reactive stromal response to prostate cancer). However, in some cases it may be necessary/advantageous to identify tissue-specific signaling mechanisms/inducers whose specific targeting is less likely to be associated with adverse side effects on healthy tissues. The observation that fibroblasts and myofibroblasts 
are interconvertible phenotypes, with phenotypic switching apparently regulated via crosstalk between $\mathrm{NOX} 4 / \mathrm{H}_{2} \mathrm{O}_{2}$ and NO signaling, has significant clinical implications. Targeting redox signaling, for example, via inhibitors of NOX4 or PDE5, antioxidants such as Se or enhancers of NO signaling, represents a promising therapeutic strategy to modulate the fibroblast/myofibroblast ratio in pathological conditions such as degenerative fibrotic diseases (Figure 3).

TGF $\beta$ unequivocally plays a central role in fibrogenesis in diverse tissues and organs. However, given its essential role in a wide range of fundamental cellular functions, there are concerns that systemic approaches directly targeting TGF $\beta$ for the treatment of fibrotic conditions will potentially exert undesirable toxic effects $[51,137]$. Indeed, this was the case in the CAT-192 clinical trial [138]. Nonetheless, several clinical trials on fibrosis employing anti-TGF $\beta$ agents have been completed and several others are underway. Unfortunately, to date, these trials have largely yielded disappointing results despite promising in vitro observations (reviewed recently $[139,140])$.

Induction of NOX4-derived $\mathrm{H}_{2} \mathrm{O}_{2}$ and reduced $\mathrm{NO}$ signaling are apparently central downstream components of TGF $\beta$-mediated myofibroblast differentiation in diverse tissues and organs. Thus, therapeutic targeting of redox homeostasis in degenerative fibrotic diseases might also be expected to elicit broad and undesirable effects. However, it should be noted that, unlike TGF $\beta$ that drives myofibroblast differentiation and fibrosis via Smad-dependent and independent pathways [51, 141], NOX4 does not modulate noncanonical signaling by TGF $\beta 1$ in prostatic fibroblasts [26, 40, 65]. Moreover, Nox4 knockout animals display no obvious basal phenotype and a dual NOX1/NOX4 inhibitor was well tolerated in animal models and in phase I clinical trials $[42,57]$. Furthermore, $\operatorname{PDE}(5)$ inhibitors are clinically employed for a variety of conditions and have a history of safe use with minimal side effects in humans [113-115].

Despite intense research efforts, there currently remains no NOX4-specific inhibitor and several attempts to generate peptides that disrupt NOX4 function have been unsuccessful with the authors concluding that, unlike other NOX isoforms, NOX4 exists in a tightly assembled and active conformation, which cannot be disrupted by conventional means [142, 143]. Nonetheless, several studies have successfully employed a dual NOX1/NOX4 inhibitor GKT137831, which showed promising results in mouse models of liver fibrosis and hypoxia-induced pulmonary hypertension $[42,57,84,144]$ and is currently entering a phase II clinical trial for diabetic nephropathy. Recently, attenuation of NOX4-dependent ROS signaling and fibrosis by sodium hydrosulfide and nifedipine (an L-type dihydropyridine calcium channel blocker) was reported in rodent models of cardiac fibrosis $[145,146]$. However, it remains to be determined whether these compounds inhibit NOX4 in a specific and isoform-selective manner or exert their effects via nonspecific and nonselective mechanisms.

Given that the signaling potential of NOX4-derived ROS is regulated by antioxidant systems, enhancing the activity of ROS scavenging enzymes may represent an alternative potential therapeutic strategy (Figure 3). Animal and human clinical data clearly demonstrate that Se deficiency or supplementation increases or reduces tumor incidence, respectively [147-152]. In addition, however, serum Se levels have been reported to be lower in patients with several different fibrotic disorders, including systemic sclerosis, primary Raynaud's phenomenon, and oral submucous fibrosis $[153,154]$. Unfortunately, there are few studies investigating the potential therapeutic benefit of Se supplementation in degenerative fibrotic disease. Although proof-of-principle is provided by reports that exogenous Se was shown to decrease hepatic fibrosis in mice [155], Se deficiency promoted thyroid fibrosis in a TGF $\beta$-dependent manner in rats [156]. However, there may be a potential increased risk of diabetes with Se supplementation [157]; thus further studies are required to better understand the biological effects of Se to allow its use in the prevention and treatment of degenerative fibrotic disease.

Inhibitors of PDE5 are clinically approved for the treatment of erectile dysfunction, pulmonary arterial hypertension, and BPH [113-115] and apparently have significant efficacy in Raynaud's phenomenon secondary to systemic sclerosis $[158,159]$. The sGC stimulator riociguat significantly improved primary and secondary endpoints in recently presented phase III clinical trials in patients with pulmonary arterial hypertension and chronic thromboembolic pulmonary hypertension $[160,161]$. Although the clinical development of the heme-independent sGC activators cinaciguat and ataciguat stopped in clinical phase II trials, the perspective to specifically activate oxidated, heme-free sGC generated by the influence of oxidative stress, seems very promising of offering novel therapies for various disorders associated with oxidative stress and several second-generation sGC activators have been developed recently $[162,163]$.

Due to the presence of multiple NOX, PDE, and GC isoforms, modulation of NOX4, PDE5, and/or sGC activities may permit continued physiological $\mathrm{H}_{2} \mathrm{O}_{2}$ and $\mathrm{NO}$ signaling. In addition, the fact that these enzymes belong to multimembered families may be clinically exploited to selectively target tissue or disease-specific isoforms. For example, selective targeting of PDE1A, that appears to play a critical role in cardiac fibrosis, led to regression of cardiac remodeling in rodents [164].

\section{Conclusions}

Fibrogenesis is widely considered the result of a dysregulated wound healing response. In particular, failure of the wave of myofibroblast apoptosis during wound healing combined with an autocrine feed-forward loop of TGF $\beta$ production leads to the development and persistence of large numbers of myofibroblasts, a hallmark of fibrotic disorders (Figure 1). TGF $\beta$ plays a key role in initiating myofibroblast differentiation from diverse precursors, most importantly fibroblasts, in a variety of organs and tissues. A large body of in vitro and in vivo data indicates that TGF $\beta$-induced myofibroblast differentiation is driven via induction of NOX4-derived ROS (Figure 2) and supported by the concomitant downregulation of Se-dependent ROS scavenging enzymes. The resulting prooxidant shift in redox homeostasis modulates 
redox-sensitive signaling cascades leading to myofibroblast differentiation (Figure 2). Interestingly, myofibroblast differentiation appears to be subject to opposing regulation via complex interplay between NOX4-derived $\mathrm{H}_{2} \mathrm{O}_{2}$ and $\mathrm{NO}$ signaling. Whilst TGF $\beta$ and NOX4-derived $\mathrm{H}_{2} \mathrm{O}_{2}$ attenuate NO signaling by impairing NOS and sGC activities and thus relieve inhibition of myofibroblast differentiation by $\mathrm{NO}$, enhancement of NO signaling prevents TGF $\beta$-induced myofibroblast differentiation (Figure 3 ). Moreover, targeting NOX4 or enhancing NO signaling induces the dedifferentiation/reversal of preexisting myofibroblasts to a quiescent fibroblast phenotype and ameliorates fibrosis in vivo indicating that fibroblasts and myofibroblasts are interconvertible phenotypes. Thus, pharmacological interference of these redox signaling processes to restore the physiological fibroblast:myofibroblast ratio offers a promising strategy for the treatment of fibrosis and degenerative fibrotic diseases. Therapeutic intervention could be potentially achieved at multiple levels, for example, by (i) targeting NOX4 directly using specific inhibitors, (ii) indirectly inhibiting NOX4 using antioxidants or Se to scavenge ROS $/ \mathrm{H}_{2} \mathrm{O}_{2}$, (iii) enhancing NO signaling via NO-donors, stimulators/activators of sGC, and/or (iv) preventing cGMP degradation using PDE inhibitors. It is hoped that the recent findings summarized herein can be applied and translated into effective therapeutic strategies for the treatment of debilitating fibrotic disorders.

$\begin{array}{ll}\text { Abbreviations } \\ \alpha \text {-SMA: } & \text { Alpha smooth muscle cell actin } \\ \text { BPH: } & \text { Benign prostatic hyperplasia } \\ \text { cAMP: } & \text { Cyclic adenosine monophosphate } \\ \text { cGMP: } & \text { Cyclic guanosine monophosphate } \\ \text { ECM: } & \text { Extracellular matrix } \\ \text { IPF: } & \text { Idiopathic pulmonary fibrosis } \\ \text { LAP: } & \text { Latency associated peptide } \\ \text { L-NAME: } & N_{\omega} \text {-Nitro-L-arginine methyl ester } \\ \text { MAPK: } & \text { Mitogen-associated protein kinase } \\ \text { NO: } & \text { Nitric oxide } \\ \text { NOS: } & \text { Nitric oxide synthase } \\ \text { NOX: } & \text { NADPH oxidase } \\ \text { PDE: } & \text { Phosphodiesterase } \\ \text { PKG: } & \text { Protein kinase G } \\ \text { PTP: } & \text { Protein tyrosine phosphatase } \\ \text { ROS: } & \text { Reactive oxygen species } \\ \text { Se: } & \text { Selenium } \\ \text { sGC: } & \text { Soluble guanylyl cyclase } \\ \text { SMC: } & \text { Smooth muscle cell } \\ \text { SNAC: } & \text { S-Nitroso- } N \text {-acetylcysteine } \\ \text { SNP: } & \text { Sodium nitroprusside } \\ \text { TGF } \beta: & \text { Transforming growth factor beta. }\end{array}$

\section{Conflict of Interests}

The authors declare that there is no conflict of interests regarding the publication of this paper.

\section{Acknowledgments}

N. Sampson is supported by an Elise Richter PostDoctoral Fellowship from the Austrian Science Fund (FWF; V216-B13). P. Berger is supported by the Austrian Science Fund (FWF; NRN S9307-B05).

\section{References}

[1] G. Gabbiani, "The myofibroblast in wound healing and fibrocontractive diseases," Journal of Pathology, vol. 200, no. 4, pp. 500-503, 2003.

[2] B. Hinz, S. H. Phan, V. J. Thannickal et al., "Recent developments in myofibroblast biology: paradigms for connective tissue remodeling," The American Journal of Pathology, vol. 180, no. 4, pp. 1340-1355, 2012.

[3] K. Kis, X. Liu, and J. S. Hagood, "Myofibroblast differentiation and survival in fibrotic disease," Expert Reviews in Molecular Medicine, vol. 13, article e27, 2011.

[4] N. Sampson, P. Berger, and C. Zenzmaier, "Therapeutic Targeting of Redox Signaling in Myofibroblast Differentiation and Age-Related Fibrotic Disease," Oxidative Medicine and Cellular Longevity, vol. 2012, Article ID 458276, 15 pages, 2012.

[5] J. L. Barnes and Y. Gorin, "Myofibroblast differentiation during fibrosis: role of NAD(P)H oxidases," Kidney International, vol. 79, no. 9, pp. 944-956, 2011.

[6] S. Bhattacharyya, J. Wei, W. G. Tourtellotte et al., "Fibrosis in systemic sclerosis: common and unique pathobiology," Fibrogenesis Tissue Repair, vol. 5, supplement 1, article S18, 2012.

[7] B. Hinz, S. H. Phan, V. J. Thannickal, A. Galli, M.-L. BochatonPiallat, and G. Gabbiani, "The myofibroblast: one function, multiple origins," The American Journal of Pathology, vol. 170, no. 6, pp. 1807-1816, 2007.

[8] P. Kong, P. Christia, and N. G. Frangogiannis, "The pathogenesis of cardiac fibrosis," Cellular and Molecular Life Sciences, vol. 71, no. 4, pp. 549-574, 2014.

[9] J. Rosenbloom, S. V. Castro, and S. A. Jimenez, "Narrative review: fibrotic diseases: cellular and molecular mechanisms and novel therapies," Annals of Internal Medicine, vol. 152, no. 3, pp. 159-166, 2010.

[10] S. Speca, I. Giusti, F. Rieder et al., "Cellular and molecular mechanisms of intestinal fibrosis," World Journal of Gastroenterology, vol. 18, no. 28, pp. 3635-3661, 2012.

[11] V. J. Thannickal, "Mechanisms of pulmonary fibrosis: role of activated myofibroblasts and NADPH oxidase," Fibrogenesis Tissue Repair, vol. 5, supplement 1, article S23, 2012.

[12] T. A. Wynn, "Cellular and molecular mechanisms of fibrosis," Journal of Pathology, vol. 214, no. 2, pp. 199-210, 2008.

[13] N. Hirota and J. G. Martin, "Mechanisms of airway remodeling," Chest, vol. 144, no. 3, pp. 1026-1032, 2013.

[14] T. H. Lan, X. Q. Huang, and H. M. Tan, "Vascular fibrosis in atherosclerosis," Cardiovascular Pathology, vol. 22, no. 5, pp. 401-407, 2013.

[15] T. Marsh, K. Pietras, and S. S. McAllister, "Fibroblasts as architects of cancer pathogenesis," Biochimica et Biophysica Acta, vol. 1832, no. 7, pp. 1070-1078, 2012.

[16] M. Otranto, V. Sarrazy, F. Bonte et al., "The role of the myofibroblast in tumor stroma remodeling," Cell Adhesion \& Migration, vol. 6, no. 3, pp. 203-219, 2012.

[17] A. Desmouliere, M. Redard, I. Darby, and G. Gabbiani, “Apoptosis mediates the decrease in cellularity during the transition 
between granulation tissue and scar," The American Journal of Pathology, vol. 146, no. 1, pp. 56-66, 1995.

[18] A. Desmoulière, C. Chaponnier, and G. Gabbiani, "Tissue repair, contraction, and the myofibroblast," Wound Repair and Regeneration, vol. 13, no. 1, pp. 7-12, 2005.

[19] S. Chabaud, M.-P. Corriveau, T. Grodzicky et al., "Decreased secretion of MMP by non-lesional late-stage scleroderma fibroblasts after selection via activation of the apoptotic faspathway," Journal of Cellular Physiology, vol. 226, no. 7, pp. 19071914, 2011.

[20] V. J. Thannickal and J. C. Horowitz, "Evolving concepts of apoptosis in idiopathic pulmonary fibrosis," Proceedings of the American Thoracic Society, vol. 3, no. 4, pp. 350-356, 2006.

[21] C. Shimbori, J. Gauldie, and M. Kolb, "Extracellular matrix microenvironment contributes actively to pulmonary fibrosis," Current Opinion in Pulmonary Medicine, vol. 19, no. 5, pp. 446452, 2013.

[22] R. Kramann, D. P. DiRocco, and B. D. Humphreys, "Understanding the origin, activation and regulation of matrixproducing myofibroblasts for treatment of fibrotic disease," The Journal of Pathology, vol. 231, no. 3, pp. 273-289, 2013.

[23] S. Ueha, F. H. Shand, and K. Matsushima, "Cellular and molecular mechanisms of chronic inflammation-associated organ fibrosis," Frontiers in Immunology, vol. 3, article 71, 2012.

[24] M. Amano, M. Nakayama, and K. Kaibuchi, "Rho-kinase/ ROCK: a key regulator of the cytoskeleton and cell polarity," Cytoskeleton, vol. 67, no. 9, pp. 545-554, 2010.

[25] J. J. Tomasek, G. Gabbiani, B. Hinz, C. Chaponnier, and R. A. Brown, "Myofibroblasts and mechano: regulation of connective tissue remodelling," Nature Reviews Molecular Cell Biology, vol. 3, no. 5, pp. 349-363, 2002.

[26] N. Sampson, R. Koziel, C. Zenzmaier et al., "ROS signaling by NOX4 drives fibroblast-to-myofibroblast differentiation in the diseased prostatic stroma," Molecular Endocrinology, vol. 25, no. 3, pp. 503-515, 2011.

[27] Y. Kojima, A. Acar, E. N. Eaton et al., "Autocrine TGF- $\beta$ and stromal cell-derived factor-1 (SDF-1) signaling drives the evolution of tumor-promoting mammary stromal myofibroblasts," Proceedings of the National Academy of Sciences of the United States of America, vol. 107, no. 46, pp. 20009-20014, 2010.

[28] T. A. Wynn, "Fibrotic disease and the TH1/TH2 paradigm," Nature Reviews Immunology, vol. 4, no. 8, pp. 583-594, 2004.

[29] M. F. Jobling, J. D. Mott, M. T. Finnegan et al., "Isoform-specific activation of latent transforming growth factor $\beta$ (LTGF- $\beta$ ) by reactive oxygen species," Radiation Research, vol. 166, no. 6, pp. 839-848, 2006.

[30] D. A. Pociask, P. J. Sime, and A. R. Brody, "Asbestos-derived reactive oxygen species activate TGF- $\beta 1$," Laboratory Investigation, vol. 84, no. 8, pp. 1013-1023, 2004.

[31] M. H. Barcellos-Hoff and T. A. Dix, "Redox-mediated activation of latent transforming growth factor- $\beta 1$," Molecular Endocrinology, vol. 10, no. 9, pp. 1077-1083, 1996.

[32] F. Grinnell and W. M. Petroll, "Cell motility and mechanics in three-dimensional collagen matrices," Annual Review of Cell and Developmental Biology, vol. 26, pp. 335-361, 2010.

[33] M. Horiguchi, M. Ota, and D. B. Rifkin, "Matrix control of transforming growth factor-beta function," Journal of Biochemistry, vol. 152, no. 4, pp. 321-329, 2012.

[34] C. Beyer and J. H. Distler, "Tyrosine kinase signaling in fibrotic disorders: translation of basic research to human disease," Biochimica et Biophysica Acta, vol. 1832, no. 7, pp. 897-904, 2013.
[35] L. A. Borthwick, T. A. Wynn, and A. J. Fisher, "Cytokine mediated tissue fibrosis," Biochimica et Biophysica Acta, vol. 1832, no. 7, pp. 1049-1060, 2013.

[36] L. Ronnov-Jessen and O. W. Petersen, "Induction of $\alpha$-smooth muscle actin by transforming growth factor- $\beta 1$ in quiescent human breast gland fibroblasts," Laboratory Investigation, vol. 68, no. 6, pp. 696-707, 1993.

[37] A. Desmouliere, A. Geinoz, F. Gabbiani, and G. Gabbiani, "Transforming growth factor- $\beta 1$ induces $\alpha$-smooth muscle actin expression in granulation tissue myofibroblasts and in quiescent and growing cultured fibroblasts," Journal of Cell Biology, vol. 122, no. 1, pp. 103-111, 1993.

[38] D. M. Peehl and R. G. Sellers, "Induction of smooth muscle cell phenotype in cultured human prostatic stromal cells," Experimental Cell Research, vol. 232, no. 2, pp. 208-215, 1997.

[39] C. D. Bondi, N. Manickam, D. Y. Lee et al., "NAD(P)H oxidase mediates TGF- $\beta 1$-induced activation of kidney myofibroblasts," Journal of the American Society of Nephrology, vol. 21, no. 1, pp. 93-102, 2010.

[40] I. Cucoranu, R. Clempus, A. Dikalova et al., "NAD(P)H oxidase 4 mediates transforming growth factor- $\beta 1$-induced differentiation of cardiac fibroblasts into myofibroblasts," Circulation Research, vol. 97, no. 9, pp. 900-907, 2005.

[41] T. R. Dunkern, D. Feurstein, G. A. Rossi, F. Sabatini, and A. Hatzelmann, "Inhibition of TGF- $\beta$ induced lung fibroblast to myofibroblast conversion by phosphodiesterase inhibiting drugs and activators of soluble guanylyl cyclase," European Journal of Pharmacology, vol. 572, no. 1, pp. 12-22, 2007.

[42] J. X. Jiang, X. Chen, N. Serizawa et al., "Liver fibrosis and hepatocyte apoptosis are attenuated by GKT137831, a novel NOX4/ NOX1 inhibitor in vivo," Free Radical Biology and Medicine, vol. 53, no. 2, pp. 289-296, 2012.

[43] J. T. Cronkhite, C. Xing, G. Raghu et al., "Telomere shortening in familial and sporadic pulmonary fibrosis," American Journal of Respiratory and Critical Care Medicine, vol. 178, no. 7, pp. 729737, 2008.

[44] A. L. Degryse, X. C. Xu, J. L. Newman et al., "Telomerase deficiency does not alter bleomycin-induced fibrosis in mice," Experimental Lung Research, vol. 38, no. 3, pp. 124-134, 2012.

[45] C. K. Garcia, "Idiopathic pulmonary fibrosis: update on genetic discoveries," Proceedings of the American Thoracic Society, vol. 8 , no. 2, pp. 158-162, 2011.

[46] J. C. Horowitz, D. S. Rogers, V. Sharma et al., "Combinatorial activation of FAK and AKT by transforming growth factor- $\beta 1$ confers an anoikis-resistant phenotype to myofibroblasts," Cellular Signalling, vol. 19, no. 4, pp. 761-771, 2007.

[47] B. Hu, D. C. Tack, T. Liu, Z. Wu, M. R. Ullenbruch, and S. H. Phan, "Role of Smad3 in the regulation of rat telomerase reverse transcriptase by TGF $\beta$," Oncogene, vol. 25, no. 7, pp. 1030-1041, 2006.

[48] H. Ikushima and K. Miyazono, "TGFB 2 signalling: a complex web in cancer progression," Nature Reviews Cancer, vol. 10, no. 6, pp. 415-424, 2010.

[49] P. Kulasekaran, C. A. Scavone, D. S. Rogers, D. A. Arenberg, V. J. Thannickal, and J. C. Horowitz, "Endothelin-1 and transforming growth factor- $\beta 1$ independently induce fibroblast resistance to apoptosis via AKT activation," American Journal of Respiratory Cell and Molecular Biology, vol. 41, no. 4, pp. 484-493, 2009.

[50] H. Li, D. Xu, J. Li, M. C. Berndt, and J.-P. Liu, "Transforming growth factor $\beta$ suppresses human telomerase reverse transcriptase (hTERT) by Smad3 interactions with c-Myc and 
the hTERT gene," Journal of Biological Chemistry, vol. 281, no. 35, pp. 25588-25600, 2006.

[51] A. Biernacka, M. Dobaczewski, and N. G. Frangogiannis, "TGF$\beta$ signaling in fibrosis," Growth Factors, vol. 29, no. 5, pp. 196202, 2011.

[52] G. Untergasser, R. Gander, C. Lilg, G. Lepperdinger, E. Plas, and P. Berger, "Profiling molecular targets of TGF- $\beta 1$ in prostate fibroblast-to-myofibroblast transdifferentiation," Mechanisms of Ageing and Development, vol. 126, no. 1, pp. 59-69, 2005.

[53] J. Folkman, M. Klagsbrun, J. Sasse, M. Wadzinski, D. Ingber, and I. Vlodavsky, "A heparin-binding angiogenic protein-basic fibroblast growth factor-is stored within basement membrane," The American Journal of Pathology, vol. 130, no. 2, pp. 393-400, 1988.

[54] G. S. Schultz and A. Wysocki, "Interactions between extracellular matrix and growth factors in wound healing," Wound Repair and Regeneration, vol. 17, no. 2, pp. 153-162, 2009.

[55] D. R. Senger, K. P. Claffey, J. E. Benes, C. A. Perruzzi, A. P. Sergiou, and M. Detmar, "Angiogenesis promoted by vascular endothelial growth factor: regulation through $\alpha 1 \beta 1$ and $\alpha 2 \beta 1$ integrins," Proceedings of the National Academy of Sciences of the United States of America, vol. 94, no. 25, pp. 13612-13617, 1997.

[56] H. J. Forman, J. M. Fukuto, T. Miller, H. Zhang, A. Rinna, and S. Levy, "The chemistry of cell signaling by reactive oxygen and nitrogen species and 4-hydroxynonenal," Archives of Biochemistry and Biophysics, vol. 477, no. 2, pp. 183-195, 2008.

[57] S. Altenhofer, P. W. Kleikers, K. A. Radermacher et al., "The NOX toolbox: validating the role of NADPH oxidases in physiology and disease," Cellular and Molecular Life Sciences, vol. 69, no. 14, pp. 2327-2343, 2012.

[58] F. Jiang, Y. Zhang, and G. J. Dusting, "NADPH oxidase-mediated redox signaling: roles in cellular stress response, stress tolerance, and tissue repair," Pharmacological Reviews, vol. 63, no. 1, pp. 218-242, 2011.

[59] K. D. Martyn, L. M. Frederick, K. Von Loehneysen, M. C. Dinauer, and U. G. Knaus, "Functional analysis of Nox4 reveals unique characteristics compared to other NADPH oxidases," Cellular Signalling, vol. 18, no. 1, pp. 69-82, 2006.

[60] S. I. Dikalov, A. E. Dikalova, A. T. Bikineyeva, H. H. H. W. Schmidt, D. G. Harrison, and K. K. Griendling, "Distinct roles of Noxl and Nox4 in basal and angiotensin II-stimulated superoxide and hydrogen peroxide production," Free Radical Biology and Medicine, vol. 45, no. 9, pp. 1340-1351, 2008.

[61] I. Takac, K. Schröder, L. Zhang et al., "The E-loop is involved in hydrogen peroxide formation by the NADPH oxidase Nox4," Journal of Biological Chemistry, vol. 286, no. 15, pp. 13304-13313, 2011.

[62] K. Bedard and K.-H. Krause, "The NOX family of ROSgenerating NADPH oxidases: physiology and pathophysiology," Physiological Reviews, vol. 87, no. 1, pp. 245-313, 2007.

[63] D. Trachootham, W. Lu, M. A. Ogasawara, N. R.-D. Valle, and P. Huang, "Redox regulation of cell survival," Antioxidants and Redox Signaling, vol. 10, no. 8, pp. 1343-1374, 2008.

[64] D. P. Jones, "Radical-free biology of oxidative stress," The American Journal of Physiology-Cell Physiology, vol. 295, no. 4, pp. C849-C868, 2008.

[65] L. Serrander, L. Cartier, K. Bedard et al., "NOX4 activity is determined by mRNA levels and reveals a unique pattern of ROS generation," Biochemical Journal, vol. 406, no. 1, pp. 105-114, 2007.
[66] N. Amara, D. Goven, F. Prost, R. Muloway, B. Crestani, and J. Boczkowski, "NOX4/NADPH oxidase expression is increased in pulmonary fibroblasts from patients with idiopathic pulmonary fibrosis and mediates TGF $\beta 1$-induced fibroblast differentiation into myofibroblasts," Thorax, vol. 65 , no. 8, pp. $733-$ 738, 2010.

[67] L. Hecker, R. Vittal, T. Jones et al., "NADPH oxidase-4 mediates myofibroblast activation and fibrogenic responses to lung injury," Nature Medicine, vol. 15, no. 9, pp. 1077-1081, 2009.

[68] K. A. Graham, M. Kulawiec, K. M. Owens et al., "NADPH oxidase 4 is an oncoprotein localized to mitochondria," Cancer Biology and Therapy, vol. 10, no. 3, pp. 223-231, 2010.

[69] J. Kuroda, T. Ago, S. Matsushima, P. Zhai, M. D. Schneider, and J. Sadoshima, "NADPH oxidase 4 (Nox4) is a major source of oxidative stress in the failing heart," Proceedings of the National Academy of Sciences of the United States of America, vol. 107, no. 35, pp. 15565-15570, 2010.

[70] B. Zhang, Z. Liu, and X. Hu, "Inhibiting cancer metastasis via targeting NAPDH oxidase 4," Biochemical Pharmacology, vol. 86, no. 2, pp. 253-266, 2013.

[71] U. Weyemi, C. E. Redon, P. R. Parekh et al., "NADPH Oxidases NOXs and DUOXs as putative targets for cancer therapy," AntiCancer Agents in Medicinal Chemistry, vol. 13, no. 3, pp. 502-514, 2013.

[72] S. J. Guo, L. Y. Wu, W. L. Shen et al., "Gene profile for differentiation of vascular adventitial myofibroblasts," Sheng Li Xue Bao, vol. 58, no. 4, pp. 337-344, 2006.

[73] R. E. Clempus, D. Sorescu, A. E. Dikalova et al., "Nox4 is required for maintenance of the differentiated vascular smooth muscle cell phenotype," Arteriosclerosis, Thrombosis, and Vascular Biology, vol. 27, no. 1, pp. 42-48, 2007.

[74] T. Hu, S. P. RamachandraRao, S. Siva et al., "Reactive oxygen species production via NADPH oxidase mediates TGF$\beta$-induced cytoskeletal alterations in endothelial cells," The American Journal of Physiology - Renal Physiology, vol. 289, no. 4, pp. F816-F825, 2005.

[75] Y. M. Moon, H. J. Kang, J. S. Cho et al., "Nox4 mediates hypoxiastimulated myofibroblast differentiation in nasal polyp-derived fibroblasts," International Archives of Allergy and Immunology, vol. 159, no. 4, pp. 399-409, 2012.

[76] B. D. Uhal, J. K. Kim, X. Li, and M. Molina-Molina, "Angiotensin-TGF- $\beta 1$ crosstalk in human idiopathic pulmonary fibrosis: autocrine mechanisms in myofibroblasts and macrophages," Current Pharmaceutical Design, vol. 13, no. 12, pp. 1247-1256, 2007.

[77] B. Crestani, V. Besnard, and J. Boczkowski, "Signalling pathways from NADPH oxidase-4 to idiopathic pulmonary fibrosis," International Journal of Biochemistry and Cell Biology, vol. 43, no. 8, pp. 1086-1089, 2011.

[78] X. F. Wei, Q. G. Zhou, F. F. Hou, B. Y. Liu, and M. Liang, "Advanced oxidation protein products induce mesangial cell perturbation through PKC-dependent activation of NADPH oxidase," The American Journal of Physiology -Renal Physiology, vol. 296, no. 2, pp. F427-F437, 2009.

[79] R.-M. Liu, J. Choi, J.-H. Wu et al., "Oxidative modification of nuclear mitogen-activated protein kinase phosphatase 1 is involved in transforming growth factor $\beta 1$-induced expression of plasminogen activator inhibitor 1 in fibroblasts," Journal of Biological Chemistry, vol. 285, no. 21, pp. 16239-16247, 2010.

[80] T. V. Murray, I. Smyrnias, A. M. Shah et al., "NADPH oxidase 4 regulates cardiomyocyte differentiation via redox activation 
of c-Jun protein and the cis-regulation of GATA-4 gene transcription," Journal of Biological Chemistry, vol. 288, no. 22, pp. 15745-15759, 2013.

[81] K. Block, A. Eid, K. K. Griendling, D.-Y. Lee, Y. Wittrant, and Y. Gorin, "Nox4 NAD(P)H oxidase mediates Src-dependent tyrosine phosphorylation of PDK-1 in response to angiotensin II: role in mesangial cell hypertrophy and fibronectin expression," Journal of Biological Chemistry, vol. 283, no. 35, pp. 2406124076, 2008.

[82] Y. Gorin, K. Block, J. Hernandez et al., "Nox4 NAD(P)H oxidase mediates hypertrophy and fibronectin expression in the diabetic kidney," Journal of Biological Chemistry, vol. 280, no. 47, pp. 39616-39626, 2005.

[83] E. R. Jarman, V. S. Khambata, C. Cope et al., "An inhibitor of NADPH oxidase- 4 attenuates established pulmonary fibrosis in a rodent disease model," The American Journal of Respiratory Cell and Molecular Biology, vol. 50, no. 1, pp. 158-169, 2014.

[84] T. Aoyama, Y. H. Paik, S. Watanabe et al., "Nicotinamide adenine dinucleotide phosphate oxidase in experimental liver fibrosis: GKT137831 as a novel potential therapeutic agent," Hepatology, vol. 56, no. 6, pp. 2316-2327, 2012.

[85] W. Zhao, T. Zhao, Y. Chen, R. A. Ahokas, and Y. Sun, "Oxidative stress mediates cardiac fibrosis by enhancing transforming growth factor-betal in hypertensive rats," Molecular and Cellular Biochemistry, vol. 317, no. 1-2, pp. 43-50, 2008.

[86] S. Carnesecchi, C. Deffert, Y. Donati et al., "A key role for NOX4 in epithelial cell death during development of lung fibrosis," Antioxidants and Redox Signaling, vol. 15, no. 3, pp. 607-619, 2011.

[87] M. Waghray, Z. Cui, J. C. Horowitz et al., "Hydrogen peroxide is a diffusible paracrine signal for the induction of epithelial cell death by activated myofibroblasts," FASEB Journal, vol. 19, no. 7, pp. 854-856, 2005.

[88] F. P. Bellinger, A. V. Raman, M. A. Reeves, and M. J. Berry, "Regulation and function of selenoproteins in human disease," Biochemical Journal, vol. 422, no. 1, pp. 11-22, 2009.

[89] M. S. Crane, A. F. Howie, J. R. Arthur, F. Nicol, L. K. Crosley, and G. J. Beckett, "Modulation of thioredoxin reductase-2 expression in EAhy926 cells: implications for endothelial selenoprotein hierarchy," Biochimica et Biophysica Acta, vol. 1790, no. 10, pp. 1191-1197, 2009.

[90] S. C. Low, E. Grundner-Culemann, J. W. Harney, and M. J. Berry, "SECIS-SBP2 interactions dictate selenocysteine incorporation efficiency and selenoprotein hierarchy," EMBO Journal, vol. 19, no. 24, pp. 6882-6890, 2000.

[91] E. Mezey, X. Liu, and J. J. Potter, “The combination of selenium and vitamin e inhibits type i collagen formation in cultured hepatic stellate cells," Biological Trace Element Research, vol. 140, no. 1, pp. 82-94, 2011.

[92] M. Bocchino, S. Agnese, E. Fagone et al., "Reactive oxygen species are required for maintenance and differentiation of primary lung fibroblasts in idiopathic pulmonary fibrosis," PLoS ONE, vol. 5, no. 11, Article ID e14003, 2010.

[93] M.-C. Vozenin-Brotons, V. Sivan, N. Gault et al., "Antifibrotic action of $\mathrm{Cu} / \mathrm{Zn}$ SOD is mediated by TGF- $\beta 1$ repression and phenotypic reversion of myofibroblasts," Free Radical Biology and Medicine, vol. 30, no. 1, pp. 30-42, 2001.

[94] F. Murad, "Nitric oxide and cyclic GMP in cell signaling and drug development," The New England Journal of Medicine, vol. 355, no. 19, pp. 2003-2011, 2006.

[95] A. J. Chu and J. K. Prasad, "Up-regulation by human recombinant transforming growth factor $\beta-1$ of collagen production in cultured dermal fibroblasts is mediated by the inhibition of nitric oxide signaling," Journal of the American College of Surgeons, vol. 188, no. 3, pp. 271-280, 1999.

[96] M. G. Ferrini, S. Rivera, J. Moon, D. Vernet, J. Rajfer, and N. F. Gonzalez-Cadavid, "The genetic inactivation of inducible nitric oxide synthase (iNOS) intensifies fibrosis and oxidative stress in the penile corpora cavernosa in type 1 diabetes," Journal of Sexual Medicine, vol. 7, no. 9, pp. 3033-3044, 2010.

[97] A. Kazakov, R. Hall, P. Jagoda et al., "Inhibition of endothelial nitric oxide synthase induces and enhances myocardial fibrosis," Cardiovascular Research, vol. 100, no. 2, pp. 211-221, 2013.

[98] D. Sun, Y. Wang, C. Liu et al., "Effects of nitric oxide on renal interstitial fibrosis in rats with unilateral ureteral obstruction," Life Sciences, vol. 90, no. 23-24, pp. 900-909, 2012.

[99] D. Vernet, M. G. Ferrini, E. G. Valente et al., "Effect of nitric oxide on the differentiation of fibroblasts into myofibroblasts in the Peyronie's fibrotic plaque and in its rat model," Nitric Oxide, vol. 7, no. 4, pp. 262-276, 2002.

[100] C. Zenzmaier, N. Sampson, D. Pernkopf, E. Plas, G. Untergasser, and P. Berger, "Attenuated proliferation and transdifferentiation of prostatic stromal cells indicate suitability of phosphodiesterase type 5 inhibitors for prevention and treatment of benign prostatic hyperplasia," Endocrinology, vol. 151, no. 8, pp. 3975-3984, 2010.

[101] R. Vercelino, I. Crespo, G. F. P. De Souza et al., "S-nitroso-Nacetylcysteine attenuates liver fibrosis in cirrhotic rats," Journal of Molecular Medicine, vol. 88, no. 4, pp. 401-411, 2010.

[102] A. Pini, S. Viappiani, M. Bolla, E. Masini, and D. Bani, "Prevention of bleomycin-induced lung fibrosis in mice by a novel approach of parallel inhibition of cyclooxygenase and nitricoxide donation using NCX 466, a prototype cyclooxygenase inhibitor and nitric-oxide donor," Journal of Pharmacology and Experimental Therapeutics, vol. 341, no. 2, pp. 493-499, 2012.

[103] C. Beyer, N. Reich, S. C. Schindler et al., "Stimulation of soluble guanylate cyclase reduces experimental dermal fibrosis," Annals of the Rheumatic Diseases, vol. 71, no. 6, pp. 1019-1026, 2012.

[104] H. Masuyama, T. Tsuruda, Y. Sekita et al., "Pressure-independent effects of pharmacological stimulation of soluble guanylate cyclase on fibrosis in pressure-overloaded rat heart," Hypertension Research, vol. 32, no. 7, pp. 597-603, 2009.

[105] Y. Wang, S. Krämer, T. Loof et al., "Stimulation of soluble guanylate cyclase slows progression in anti-thyl-induced chronic glomerulosclerosis," Kidney International, vol. 68, no. 1, pp. 4761, 2005.

[106] Y. Wang, S. Krämer, T. Loof et al., "Enhancing cGMP in experimental progressive renal fibrosis: soluble guanylate cyclase stimulation vs. phosphodiesterase inhibition," The American Journal of Physiology-Renal Physiology, vol. 290, no. 1, pp. F167-F176, 2006.

[107] S. Geschka, A. Kretschmer, Y. Sharkovska et al., "Soluble guanylate cyclase stimulation prevents fibrotic tissue remodeling and improves survival in salt-sensitive dahl rats," PLOS ONE, vol. 6, no. 7, Article ID e21853, 2011.

[108] Y. Sharkovska, P. Kalk, B. Lawrenz et al., "Nitric oxideindependent stimulation of soluble guanylate cyclase reduces organ damage in experimental low-renin and high-renin models," Journal of Hypertension, vol. 28, no. 8, pp. 1666-1675, 2010.

[109] H. H. Schmidt, P. M. Schmidt, and J. P. Stasch, "NO- and haemindependent soluble guanylate cyclase activators," in cGMP: Generators, Effectors and Therapeutic Implications, vol. 191 of Handbook of Experimental Pharmacology, pp. 309-339, 2009. 
[110] A. Knorr, C. Hirth-Dietrich, C. Alonso-Alija et al., "Nitric oxide-independent activation of soluble guanylate cyclase by BAY 60-2770 in experimental liver fibrosis," ArzneimittelForschung/Drug Research, vol. 58, no. 2, pp. 71-80, 2008.

[111] P. Kalk, M. Godes, K. Relle et al., "NO-independent activation of soluble guanylate cyclase prevents disease progression in rats with 5/6 nephrectomy," British Journal of Pharmacology, vol. 148, no. 6, pp. 853-859, 2006.

[112] P. Li, D. Wang, J. Lucas et al., "Atrial natriuretic peptide inhibits transforming growth factor $\beta$-induced Smad signaling and myofibroblast transformation in mouse cardiac fibroblasts," Circulation Research, vol. 102, no. 2, pp. 185-192, 2008.

[113] J. Houtchens, D. Martin, and J. R. Klinger, "Diagnosis and management of pulmonary arterial hypertension," Pulmonary Medicine, vol. 2011, Article ID 845864, 13 pages, 2011.

[114] M. Oelke, F. Giuliano, V. Mirone, L. Xu, D. Cox, and L. Viktrup, "Monotherapy with tadalafil or tamsulosin similarly improved lower urinary tract symptoms suggestive of benign prostatic hyperplasia in an international, randomised, parallel, placebocontrolled clinical trial," European Urology, vol. 61, no. 5, pp. 917-925, 2012.

[115] R. C. Rosen and J. B. Kostis, "Overview of phosphodiesterase 5 inhibition in erectile dysfunction," The American Journal of Cardiology, vol. 92, no. 9, supplement 1, pp. 9-18, 2003.

[116] B. Hohenstein, C. Daniel, S. Wittmann, and C. Hugo, "PDE5 inhibition impedes TSP-1 expression, TGF- $\beta$ activation and matrix accumulation in experimental glomerulonephritis," Nephrology Dialysis Transplantation, vol. 23, no. 11, pp. 34273436, 2008.

[117] M. G. Ferrini, I. Kovanecz, G. Nolazco, J. Rajfer, and N. F. Gonzalez-Cadavid, "Effects of long-term vardenafil treatment on the development of fibrotic plaques in a rat model of Peyronie's disease," BJU International, vol. 97, no. 3, pp. 625-633, 2006.

[118] E. G. A. Valente, D. Vernet, M. G. Ferrini, A. Qian, J. Rajfer, and N. F. Gonzalez-Cadavid, "L-Arginine and phosphodiesterase (PDE) inhibitors counteract fibrosis in the Peyronie's fibrotic plaque and related fibroblast cultures," Nitric Oxide, vol. 9, no. 4, pp. 229-244, 2003.

[119] C. Zenzmaier, J. Kern, N. Sampson et al., "Phosphodiesterase type 5 inhibition reverts prostate fibroblast-to-myofibroblast trans-differentiation," Endocrinology, vol. 153, no. 11, pp. 55465555, 2013.

[120] J. T. Stefano, B. Cogliati, F. Santos et al., "S-Nitroso-N-acetylcysteine induces de-differentiation of activated hepatic stellate cells and promotes antifibrotic effects in vitro," Nitric Oxide, vol. 25, no. 3, pp. 360-365, 2011.

[121] Y. Wang-Rosenke, A. Mika, D. Khadzhynov, T. Loof, H.-H. Neumayer, and H. Peters, "Stimulation of soluble guanylate cyclase improves renal recovery after relief of unilateral ureteral obstruction," Journal of Urology, vol. 186, no. 3, pp. 1142-1149, 2011.

[122] K. Block and Y. Gorin, "Aiding and abetting roles of NOX oxidases in cellular transformation," Nature Reviews Cancer, vol. 12, no. 9, pp. 627-637, 2012.

[123] G. M. Rubanyi and P. M. Vanhoutte, "Superoxide anions and hyperoxia inactivate endothelium-derived relaxing factor," The American Journal of Physiology, vol. 250, no. 5, pp. H822-H827, 1986.

[124] N. D. Roe and J. Ren, "Nitric oxide synthase uncoupling: a therapeutic target in cardiovascular diseases," Vascular Pharmacology, vol. 57, no. 5-6, pp. 168-172, 2012.
[125] N. S. R. De Mochel, S. Seronello, S. H. Wang et al., "Hepatocyte $\mathrm{NAD}(\mathrm{P}) \mathrm{H}$ oxidases as an endogenous source of reactive oxygen species during hepatitis C virus infection," Hepatology, vol. 52, no. 1, pp. 47-59, 2010.

[126] N. Ito, U. T. Ruegg, A. Kudo et al., "Activation of calcium signaling through Trpv1 by nNOS and peroxynitrite as a key trigger of skeletal muscle hypertrophy," Nature Medicine, vol. 19, no. 1, pp. 101-106, 2013.

[127] A. A. Eid, D. Y. Lee, L. J. Roman et al., "Sestrin 2 and AMPK connect hyperglycemia to Nox4-dependent endothelial nitric oxide synthase uncoupling and matrix protein expression," Molecular and Cellular Biology, vol. 33, no. 17, pp. 3439-3460, 2013.

[128] D. Y. Lee, F. Wauquier, A. A. Eid et al., "Nox4 NADPH oxidase mediates peroxynitrite-dependent uncoupling of endothelial nitric-oxide synthase and fibronectin expression in response to angiotensin II: role of mitochondrial reactive oxygen species," Journal of Biological Chemistry, vol. 288, no. 40, pp. 2866828686, 2013.

[129] E. A. Jaimes, C. Sweeney, and L. Raij, "Effects of the reactive oxygen species hydrogen peroxide and hypochlorite on endothelial nitric oxide production," Hypertension, vol. 38 , no. 4, pp. $877-$ 883, 2001.

[130] C. Gerassimou, A. Kotanidou, Z. Zhou, D. D. C. Simoes, C. Roussos, and A. Papapetropoulos, "Regulation of the expression of soluble guanylyl cyclase by reactive oxygen species," British Journal of Pharmacology, vol. 150, no. 8, pp. 1084-1091, 2007.

[131] S. Wedgwood, R. H. Steinhorn, M. Bunderson et al., "Increased hydrogen peroxide downregulates soluble guanylate cyclase in the lungs of lambs with persistent pulmonary hypertension of the newborn," The American Journal of Physiology-Lung Cellular and Molecular Physiology, vol. 289, no. 4, pp. L660-L666, 2005.

[132] S. Meurer, S. Pioch, S. Gross, and W. Müller-Esterl, "Reactive oxygen species induce tyrosine phosphorylation of and Src kinase recruitment to NO-sensitive guanylyl cyclase," Journal of Biological Chemistry, vol. 280, no. 39, pp. 33149-33156, 2005.

[133] K. S. Murthy, "Inhibitory phosphorylation of soluble guanylyl cyclase by muscarinic $\mathrm{m} 2$ receptors via $\mathrm{G} \beta \gamma$-dependent activation of c-Src kinase," Journal of Pharmacology and Experimental Therapeutics, vol. 325, no. 1, pp. 183-189, 2008.

[134] T. Adachi, R. Matsui, R. M. Weisbrod, S. Najibi, and R. A. Cohen, "Reduced sarco/endoplasmic reticulum $\mathrm{Ca}^{2+}$ uptake activity can account for the reduced response to NO, but not sodium nitroprusside, in hypercholesterolemic rabbit aorta," Circulation, vol. 104, no. 9, pp. 1040-1045, 2001.

[135] X. Tong, X. Hou, D. Jourd'Heuil, R. M. Weisbrod, and R. A. Cohen, "Upregulation of Nox 4 by TGF $\beta 1$ oxidizes SERCA and inhibits NO in arterial smooth muscle of the prediabetic zucker rat," Circulation Research, vol. 107, no. 8, pp. 975-983, 2010.

[136] J. Ying, X. Tong, D. R. Pimentel et al., "Cysteine-674 of the sarco/ endoplasmic reticulum calcium ATPase is required for the inhibition of cell migration by nitric oxide," Arteriosclerosis, Thrombosis, and Vascular Biology, vol. 27, no. 4, pp. 783-790, 2007.

[137] A. Leask, "Potential therapeutic targets for cardiac fibrosis: TGF $\beta$, angiotensin, endothelin, CCN2, and PDGF, partners in fibroblast activation," Circulation Research, vol. 106, no. 11, pp. 1675-1680, 2010.

[138] C. P. Denton, P. A. Merkel, D. E. Furst et al., "Recombinant human anti-transforming growth factor $\beta 1$ antibody therapy 
in systemic sclerosis: a multicenter, randomized, placebocontrolled phase I/II trial of CAT-192," Arthritis and Rheumatism, vol. 56, no. 1, pp. 323-333, 2007.

[139] J. Rosenbloom, F. A. Mendoza, and S. A. Jimenez, "Strategies for anti-fibrotic therapies," Biochimica et Biophysica Acta, vol. 1832, no. 7, pp. 1088-1103, 2013.

[140] L. A. Van Meeteren and P. Ten Dijke, "Regulation of endothelial cell plasticity by TGF- $\beta$," Cell and Tissue Research, vol. 347, no. 1, pp. 177-186, 2012.

[141] Y. E. Zhang, "Non-Smad pathways in TGF- $\beta$ signaling," Cell Research, vol. 19, no. 1, pp. 128-139, 2009.

[142] G. Csanyi and P. J. Pagano, "Strategies aimed at Nox4 oxidase inhibition employing peptides from Nox4 B-loop and Cterminus and $\mathrm{p} 22^{\text {phox }} \mathrm{N}$-terminus: an elusive target," International Journal of Hypertension, vol. 2013, Article ID 842827, 9 pages, 2013.

[143] I. Dahan and E. Pick, "Strategies for identifying synthetic peptides to act as inhibitors of NADPH oxidases, or "All that you did and did not want to know about Nox inhibitory peptides"' Cellular and Molecular Life Sciences, vol. 69, no. 14, pp. 22832305, 2012.

[144] D. E. Green, T. C. Murphy, B. Y. Kang et al., "The Nox4 inhibitor GKT137831 attenuates hypoxia-induced pulmonary vascular cell proliferation," American Journal of Respiratory Cell and Molecular Biology, vol. 47, no. 5, pp. 718-726, 2012.

[145] Y. Jia, J. Xu, Y. Yu et al., "Nifedipine inhibits angiotensin IIinduced cardiac fibrosis via downregulating Nox4-derived ROS generation and suppressing ERK1/2, JNK signaling pathways," Pharmazie, vol. 68, no. 6, pp. 435-441, 2013.

[146] L. L. Pan, X. H. Liu, Y. Q. Shen et al., "Inhibition of NADPH oxidase 4-related signaling by sodium hydrosulfide attenuates myocardial fibrotic response," International Journal of Cardiology, vol. 168, no. 4, pp. 3770-3778, 2013.

[147] V. Diwadkar-Navsariwala, G. S. Prins, S. M. Swanson et al., "Selenoprotein deficiency accelerates prostate carcinogenesis in a transgenic model," Proceedings of the National Academy of Sciences of the United States of America, vol. 103, no. 21, pp. 81798184, 2006.

[148] B. C. Pence, E. Delver, and D. M. Dunn, "Effects of dietary selenium on UVB-induced skin carcinogenesis and epidermal antioxidant status," Journal of Investigative Dermatology, vol. 102, no. 5, pp. 759-761, 1994.

[149] M. Selenius, A.-K. Rundlöf, E. Olm, A. P. Fernandes, and M. Björnstedt, "Selenium and the selenoprotein thioredoxin reductase in the prevention, treatment and diagnostics of cancer," Antioxidants and Redox Signaling, vol. 12, no. 7, pp. 867-880, 2010.

[150] A. J. Duffield-Lillico, B. L. Dalkin, M. E. Reid et al., "Selenium supplementation, baseline plasma selenium status and incidence of prostate cancer: an analysis of the complete treatment period of the Nutritional Prevention of Cancer Trial," BJU International, vol. 91, no. 7, pp. 608-612, 2003.

[151] R. Hurst, L. Hooper, T. Norat et al., "Selenium and prostate cancer: systematic review and meta-analysis," The American Journal of Clinical Nutrition, vol. 96, no. 1, pp. 111-122, 2012.

[152] M. S. Geybels, B. A. Verhage, F. J. van Schooten et al., "Advanced prostate cancer risk in relation to toenail selenium levels," Journal of the National Cancer Institute, vol. 105, no. 18, pp. 13941401, 2013.

[153] A. L. Herrick, F. Rieley, D. Schofield, S. Hollis, J. M. Braganza, and M. I. V. Jayson, "Micronutrient antioxidant status in patients with primary Raynaud's phenomenon and systemic sclerosis," Journal of Rheumatology, vol. 21, no. 8, pp. 1477-1483, 1994.

[154] S. Khanna, A. C. Udas, G. K. Kumar et al., "Trace elements (copper, zinc, selenium and molybdenum) as markers in oral sub mucous fibrosis and oral squamous cell carcinoma," Journal of Trace Elements in Medicine and Biology, vol. 27, no. 4, pp. 307311, 2013.

[155] M. Ding, J. J. Potter, X. Liu, M. S. Torbenson, and E. Mezey, "Selenium supplementation decreases hepatic fibrosis in mice after chronic carbon tetrachloride administration," Biological Trace Element Research, vol. 133, no. 1, pp. 83-97, 2010.

[156] B. Contempre, O. Le Moine, J. E. Dumont, J.-F. Denef, and M. C. Many, "Selenium deficiency and thyroid fibrosis. A key role for macrophages and transforming growth factor $\beta$ (TGF- $\beta$ )," Molecular and Cellular Endocrinology, vol. 124, no. 1-2, pp. 7-15, 1996.

[157] M. P. Rayman and S. Stranges, "Epidemiology of selenium and type 2 diabetes: can we make sense of it?" Free Radical Biology and Medicine, vol. 65, pp. 1557-1564, 2013.

[158] A. J. Impens, K. Phillips, and E. Schiopu, "PDE-5 inhibitors in scleroderma raynaud phenomenon and digital ulcers: current status of clinical trials," International Journal of Rheumatology, vol. 2011, Article ID 392542, 2011.

[159] M. Roustit, S. Blaise, Y. Allanore et al., "Phosphodiesterase-5 inhibitors for the treatment of secondary Raynaud's phenomenon: systematic review and meta-analysis of randomised trials," Annals of the Rheumatic Diseases, vol. 72, no. 10, pp. 1696-1699, 2013.

[160] H. A. Ghofrani, A. M. D’Armini, F. Grimminger et al., "Riociguat for the treatment of chronic thromboembolic pulmonary hypertension," The New England Journal of Medicine, vol. 369, no. 4, pp. 319-329, 2013.

[161] H. A. Ghofrani, N. Galie, F. Grimminger et al., "Riociguat for the treatment of pulmonary arterial hypertension," The New England Journal of Medicine, vol. 369, no. 4, pp. 330-340, 2013.

[162] M. Follmann, N. Griebenow, M. G. Hahn et al., "The chemistry and biology of soluble guanylate cyclase stimulators and activators," Angewandte Chemie International Edition, vol. 52, no. 36, pp. 9442-9462, 2013.

[163] M. Gheorghiade, S. J. Greene, G. Filippatos et al., "Cinaciguat, a soluble guanylate cyclase activator: results from the randomized, controlled, phase IIb COMPOSE programme in acute heart failure syndromes," European Journal of Heart Failure, vol. 14, no. 9, pp. 1056-1066, 2012.

[164] C. L. Miller, Y. Cai, M. Oikawa et al., "Cyclic nucleotide phosphodiesterase 1A: a key regulator of cardiac fibroblast activation and extracellular matrix remodeling in the heart," Basic Research in Cardiology, vol. 106, no. 6, pp. 1023-1039, 2011. 

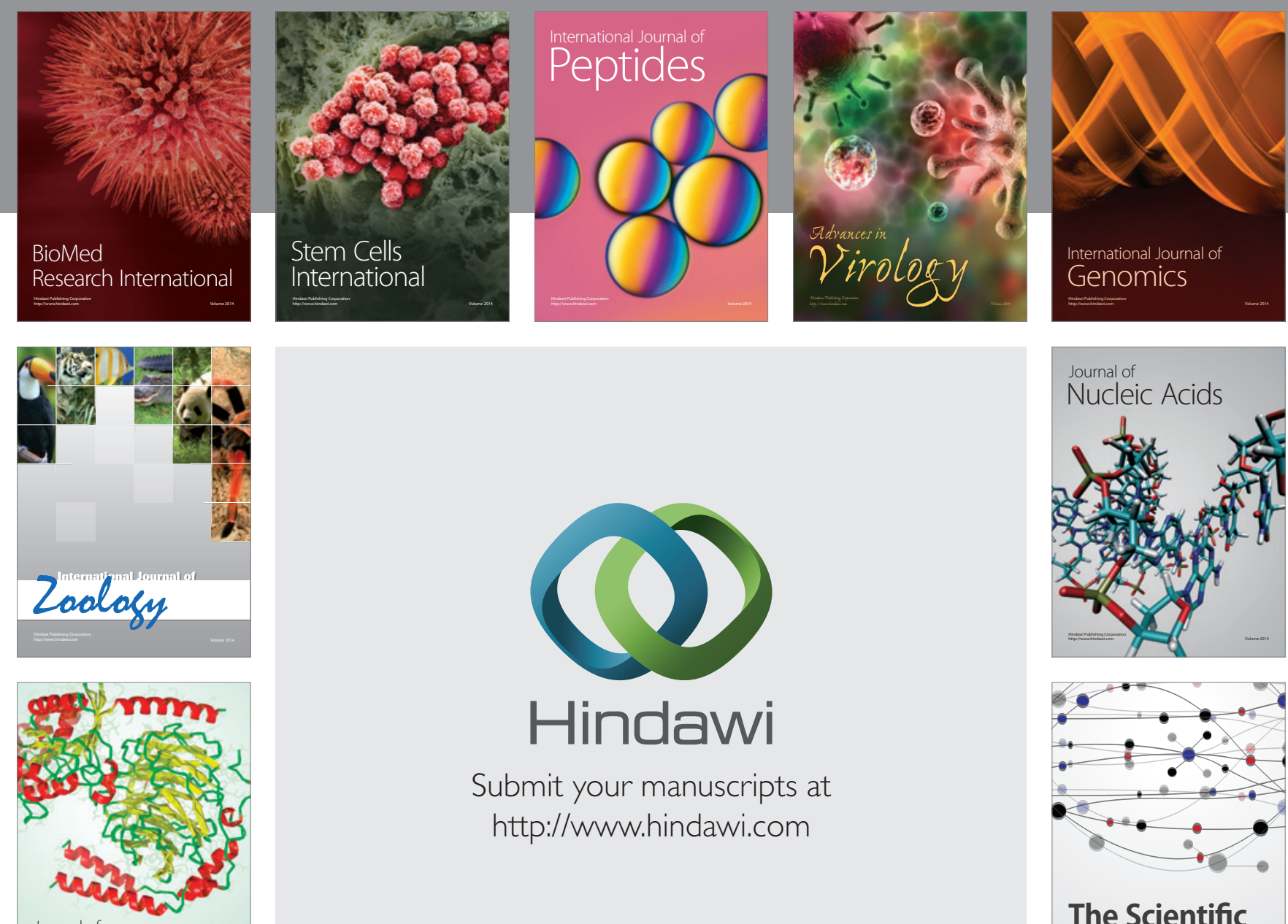

Submit your manuscripts at

http://www.hindawi.com

Journal of
Signal Transduction
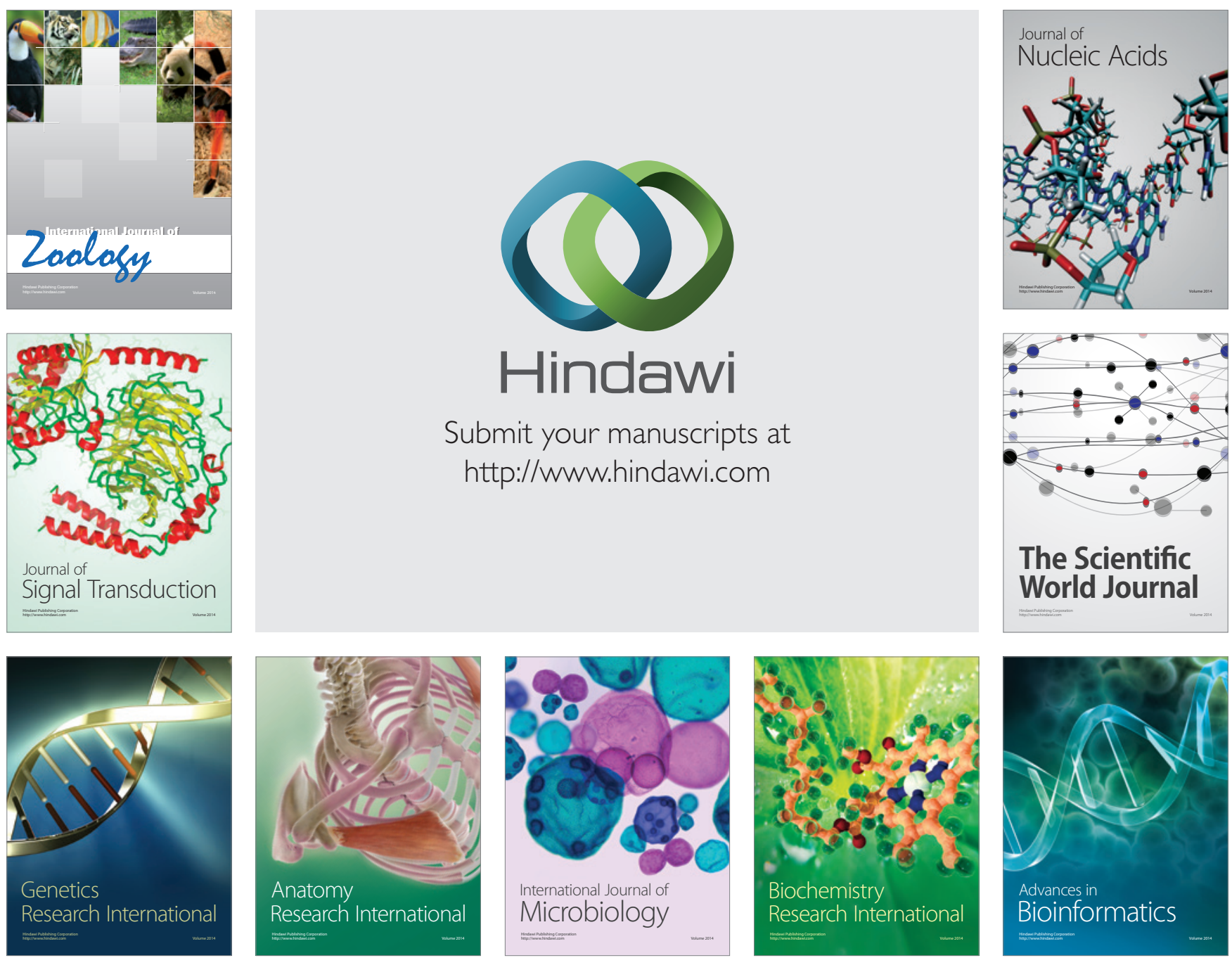

The Scientific World Journal
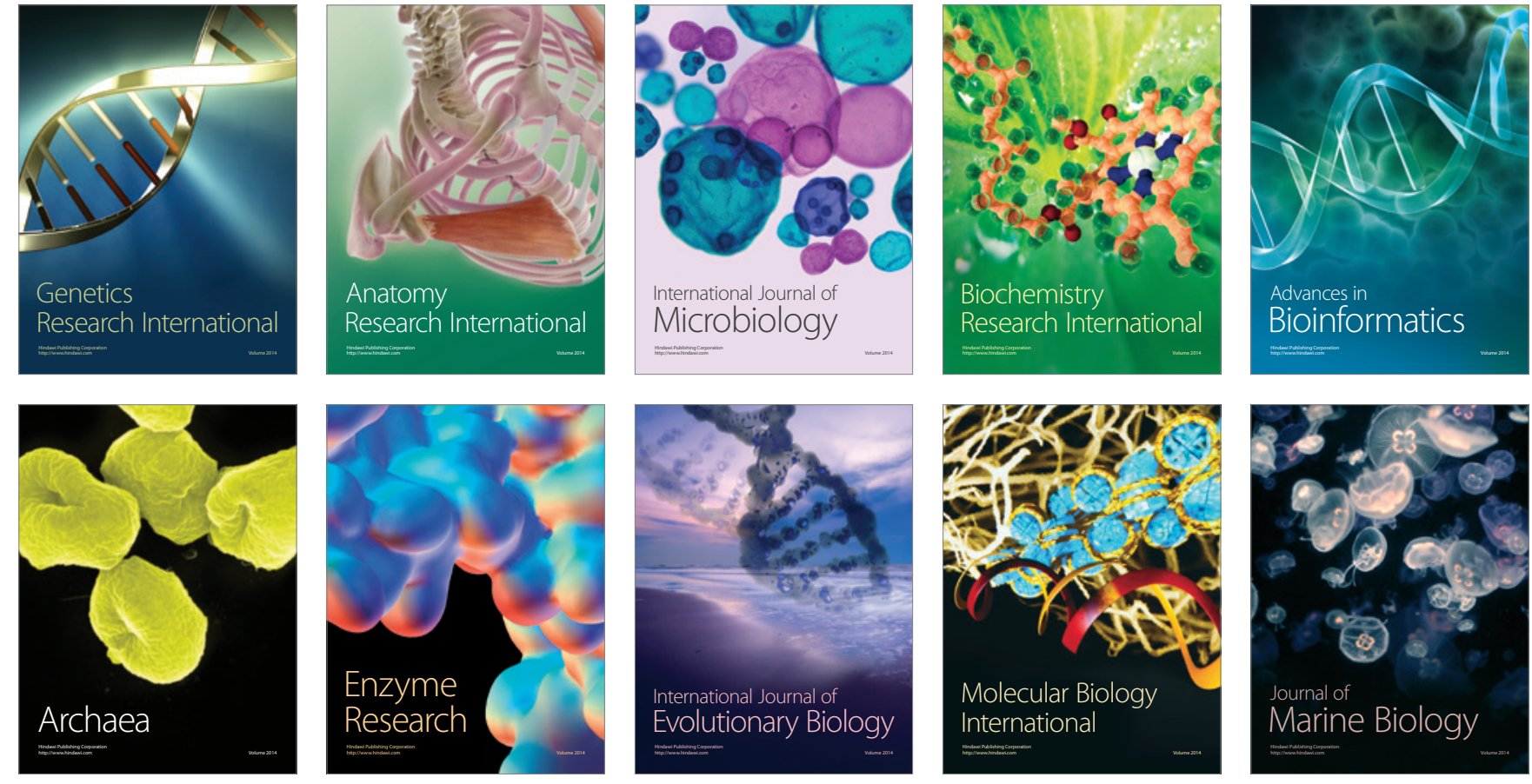